\title{
Atomic data from the Iron Project
}

\section{Relativistic allowed and forbidden transition probabilities for Fe XVII}

\author{
Sultana N. Nahar ${ }^{1}$, Werner Eissner ${ }^{2}$, Guo-Xin Chen ${ }^{1}$, and Anil K. Pradhan ${ }^{1}$ \\ 1 Department of Astronomy, The Ohio State University, Columbus, OH 43210, USA \\ 2 Institut für Theoretische Physik, Teilinstitut 1, 70550 Stuttgart, Germany
}

Received 25 February 2003 / Accepted 4 June 2003

\begin{abstract}
An extensive set of fine structure levels and corresponding transition probabilities for allowed and forbidden transitions in Fe XVII is presented. A total of 490 bound energy levels of Fe XVII of total angular momenta $0 \leq J \leq 7$ of even and odd parities with $2 \leq n \leq 10,0 \leq l \leq 8,0 \leq L \leq 8$, and singlet and triplet multiplicities, are obtained. They translate to over $2.6 \times 10^{4}$ allowed (E1) transitions that are of dipole and intercombination type, and 2312 forbidden transitions that include electric quadrupole (E2), magnetic dipole (M1), electric octopole (E3), and magnetic quadrupole (M2) type representing the most detailed calculations to date for the ion. Oscillator strengths $f$, line strengths $S$, and coefficients $A$ of spontaneous emission for the E1 type transitions are obtained in the relativistic Breit-Pauli R-matrix approximation. $A$-values for the forbidden transitions are obtained from atomic structure calculations using codes SUPERSTRUCTURE and GRASP. The energy levels are identified in spectroscopic notation with the help of a newly developed level identification algorithm. Nearly all 52 spectroscopically observed levels have been identified, their binding energies agreeing within $1 \%$ with our calculation. Computed transition probabilities are compared with other calculations and measurement. The effect of 2-body magnetic terms and other interactions is discussed. The present data set enhances by more than an order of magnitude the heretofore available data for transition probabilities of Fe XVII.
\end{abstract}

Key words. atomic data - radiation mechanisms: general - X-ray: general

\section{Introduction}

Ne-like Fe XVII attracts great astrophysical interest with some of the most prominent spectral lines in the X-ray and the EUV regimes. These lines are abundantly evident from diverse sources such as the solar corona and other stellar coronae (e.g. Brickhouse et al. 2001), and active galactic nuclei (e.g. Lee et al. 2001). Fe XVII also plays a role in benchmarking laboratory experiments and theoretical calculations. Recent Iron Project (IP, Hummer et al. 1993) work has included the computation of collision strengths and rate coefficients by electron impact excitation of Fe XVII and diagnostics of laboratory and astrophysical spectra (Chen \& Pradhan 2002; Chen et al. 2002 - hereafter CPE02). Spectral analysis moreover requires transition probabilities for observed allowed and forbidden transitions. Transition probablities are also required to account for

Send offprint requests to: Sultana N. Nahar, e-mail: nahar@astronomy.ohio-state.edu

* Complete electronic data tables of energies and transition probabilities are only available in electronic form at the CDS via anonymous ftp to cdsarc.u-strasbg.fr $(130.79 .128 .5)$ or via http://cdsweb.u-strasbg.fr/cgi-bin/qcat?J/A+A/408/789 radiative cascades from higher levels that contribute to level populations; cascades generally proceed via strong dipole allowed transitions, and may entail fairly highly excited levels. Therefore a fairly large and complete set of data is needed for astrophysical models of Fe XVII.

Smaller sets of transitions are available from other sources. An evaluated compilation of data, obtained by various investigators using different approximations, can be found in the National Institute for Standards and Technology database (NIST: www .nist.gov). A previous set of non-relativistic data for Fe XVII was obtained by M. P. Scott under the Opacity Project (OP 1995, 1996), which are accessible through the OP database, TOPbase (Cunto et al. 1993). These results are in $L S$ coupling and consider only the dipole allowed $L S$ multiplets; no relativistic effects are taken into account.

The present calculations are carried out for extensive sets of oscillator strengths, line strengths, and transition probabilities of dipole allowed, intercombination, and forbidden electric quadrupole and octopole, magnetic dipole and quadrupole fine structure (FS) transitions in Fe XVII up to $n \leq 10$. Transitions of type E1 are obtained in the relativistic BreitPauli R-matrix method developed under the Iron Project. 
Configuration mixing type atomic structure calculations, using codes SUPERSTRUCTURE (Eissner et al. 1974) and GRASP (Parpia et al. 1996) which is based upon the multiconfiguration Dirac-Fock (MCDF) method, are employed for the forbidden E2, E3, and M1, M2 transitions. One of the primary tasks is the spectroscopic identification of levels and lines of E1 transitions. We apply the recently developed techniques (Nahar \& Pradhan 2000) for a reasonably complete spectroscopic dataset to Fe XVII.

\section{Formulation}

We employ the relativistic Breit-Pauli $R$-matrix (BPRM) approach in a collision type calculation for bound states followed by computing radiative processes: Scott \& Burke 1980; Scott \& Taylor 1982; Hummer et al. 1993; Berrington et al. 1995. Unlike calculations in $L S$ coupling, when radiative transition amplitudes vanish unless $\Delta S=0$, intermediate coupling calculations include intercombination lines.

Details of this close coupling (CC) approach to radiative processes are discussed in earlier papers, such as in the first large scale relativistic BPRM calculations for bound-bound transitions in Fe XXIV and Fe XXV (Nahar \& Pradhan 1999), Fe V (Nahar et al. 2000), Ar XIII and Fe XXI (Nahar 2000). In the present work electric octopole and magnetic dipole transitions are considered for the first time in the IP series. A brief outline of the formulation is henceforth given.

The wavefunction $\Psi(E)$ for the $(N+1)$ electron system with total spin and orbital angular momenta symmetry $S L \pi$ or total angular momentum symmetry $J \pi$ is expanded in terms of "frozen" $N$-electron target ion functions $\chi_{i}$ and vector coupled collision electrons $\theta_{i}$,

$\Psi_{\mathrm{E}}(\mathrm{e}+$ ion $)=\mathcal{A} \sum_{i} \chi_{i}($ ion $) \theta_{i}+\sum_{j} c_{j} \Phi_{j}(\mathrm{e}+$ ion $)$,

in some specific state $S_{i} L_{i} \pi_{i}$ or level $J_{i} \pi_{i}$, index $i$ marking channels $S_{i} L_{i}\left(J_{i}\right) \pi_{i} k_{i}^{2} \ell_{i}(S L \pi$ or $J \pi)$ with energy $k_{i}^{2}$ of the colliding electron. The second sum expands correlation functions $\Phi_{j}$ as products with $N+1$ bound orbital functions that (a) compensate for the orthogonality conditions between the continuum and the bound orbitals, and (b) represent additional short-range correlation that is often of crucial importance in scattering and radiative CC calculations for each $S L \pi$.

In IP work we restrict the $(N+1)$-electron Breit-Pauli Hamiltonian to

$H_{N+1}^{\mathrm{BP}}=H_{N+1}^{\mathrm{NR}}+H_{N+1}^{\mathrm{mass}}+H_{N+1}^{\mathrm{Dar}}+H_{N+1}^{\mathrm{so}}$,

where $H_{N+1}^{\mathrm{NR}}$ is the non-relativistic Hamiltonian

$H_{N+1}^{\mathrm{NR}}=\sum_{i=1}^{N+1}\left\{-\nabla_{i}^{2}-\frac{2 Z}{r_{i}}+\sum_{j>i}^{N+1} \frac{2}{r_{i j}}\right\}$

Among the three 1-body terms of Breit-Pauli order the massvelocity and the Darwin term does not break $L S$ symmetry while improving energy positions, whereas terms involving the magnetic moment of electrons split terms $L S$ into fine-structure levels $J \pi$ :

$$
\begin{aligned}
& H^{\mathrm{mass}}=-\frac{\alpha^{2}}{4} \sum_{i} p_{i}^{4}, \quad H^{\mathrm{Dar}}=\frac{\alpha^{2}}{4} \sum_{i} \nabla^{2}\left(\frac{Z}{r_{i}}\right), \\
& H^{\mathrm{so}}=\alpha^{2} \sum_{i=1} \frac{Z}{r_{i}^{3}} l(i) \cdot s(i) \Rightarrow \sum_{q \max +1} \zeta_{n l}^{\mathrm{BW}} l(i) \cdot s(i),
\end{aligned}
$$

" $\Rightarrow$ " indicating that mutual spin-orbit and spin-other-orbit interaction with $q$ max closed shell electrons is accounted for in an ordinary spin-orbit parameter $\zeta_{n l}^{\mathrm{BW}}$ for the valence electrons as a screening effect (Blume \& Watson 1962). Unlike SUPERSTRUCTURE the current BPRM code ignores the BP 2-body spin-orbit, spin-other-orbit and spin-spin terms between $v a$ lence shell electrons.

$R$-matrix solutions of coupled equations to total symmetries $L S$ are recoupled in a pair coupling scheme on adding spin-orbit interaction to obtain $(\mathrm{e}+\mathrm{ion})$ states of total $J \pi$, in the end yielding $(N+1)$-electron solutions

$H_{N+1}^{\mathrm{BP}} \Psi=E \Psi$.

Rather than dealing with positive energies $(E>0)$ as in ordinary collision processes we focus on an eigenvalue problem $(E<0)$ for the electron described by $\theta$, leading to discrete bound states $\Psi_{\mathrm{B}}$.

The primary quantity expressing radiative excitation or deexcitation in a weak field is the line strength

$S^{\mathrm{X} \lambda}(i j)=\left|\left\langle\Psi_{j}\left\|O^{\mathrm{X} \lambda}\right\| \Psi_{i}\right\rangle\right|^{2}, \quad S(j i)=S(i j)$.

For electric multipole transitions in the length formulation (and long wave-length approximation) it does not explicitly depend upon the transition energy, as

$O^{\mathrm{E} \lambda}=b^{[\lambda]} \sum_{p=1}^{N+1} \mathrm{C}^{[\lambda]}(p) r_{p}^{\lambda}, \quad b^{[\lambda]}=\sqrt{\frac{2}{\lambda+1}}$.

Transition probabilities $A$ and absorption oscillator strengths ( $f$-values) between bound states $i$ and $j$ and excitation energy $E_{i j}=E_{j}-E_{i}$ are written in terms of the line strength $S$, observing that Eq. (3) implies scaling of energies in units of $\mathrm{Ry}=\frac{\alpha^{2}}{2} m_{\mathrm{el}} c^{2}=13.6 \mathrm{eV}$, hence time unit $\tau_{0}=\hbar / \mathrm{Ry}=$ $4.838 \times 10^{-17} \mathrm{~s}$ :

$f_{i j}=\frac{E_{j i}}{3 g_{i}} S^{\mathrm{E} 1}(i j), \quad g_{i} f_{i j}=-g_{j} f_{j i}=(g f)_{i j}$

$A_{j i}^{\mathrm{E} 1} \cdot \tau_{0}=\alpha^{3} \frac{g_{i}}{g_{j}} E_{j i}^{2} f_{i j}$

in the case of electric dipole radiation $\mathrm{E} \lambda=\mathrm{E} 1$. The symbols in these equations have their usual meaning, in particular $g_{j}$ and $g_{i}$ being the statistical weights of the upper and lower states respectively. Hypervirial identities arising from the commutator $[r H]_{-}$yield alternative formulations, velocity formulation for a start, that probe the radial wave functions less far out. With $H^{\mathrm{NR}}$ it leads to simple substitutions of $r^{\lambda}$ in Eq. (7) - but to additional terms of order $\alpha^{2}$ for $H^{\mathrm{BP}}$ ! BPRM ignores such "velocity" terms: they are not large enough though for Fe XVII to render comparison of length with velocity results a useless 
tool (yet better left to NR-results). In the magnetic dipole case the radiative operator to the line strength expression (6) reads

$O^{\mathrm{M} 1}=\sum_{p} l(p)+2 s(p)+\frac{\alpha^{2}}{2}\left\{\frac{\partial^{2}}{\partial r_{p}^{2}}+\ldots+\sum_{p^{\prime}>p} \frac{\ldots}{r_{p^{\prime} p}}\right\} ;$

where the sum runs over electron coordinates, $l$ and $s$ are the orbital and spin operators respectively. Details on the correction of relative BP order can be found in O II work of 1981 by Eissner and Zeippen. Magnetic quadrupole $(\lambda=2)$ radiation is treated to lowest order, i.e.

$O^{\mathrm{M} \lambda}=b^{[\lambda]} \sum_{p} r_{p}^{\lambda-1}\left[C^{[\lambda-1]}(p) \times\{l(p)+(\lambda+1) s(p)\}\right]^{[\lambda]}$.

The lifetime of a level can be computed as

$\tau_{k}=\frac{1}{A_{k}}$

where $A_{k}=\sum_{i} A_{k i}$

is the total radiative transition probability for level $k$, i.e.

$g_{i} A_{k i}^{\mathrm{E} 1}=2.6774 \times 10^{9} \mathrm{~s}^{-1}\left(E_{i}-E_{k}\right)^{3} S^{\mathrm{E} 1}(i, k)$

(the observed rate) in the electric dipole case E1. The Einstein coefficients for spontaneous decay by higher order multipole radiation that need be considered for transitions down to the $10 \AA$ range read as follows:

electric quadrupole (E2) and magnetic dipole (M1)

$g_{j} A_{j i}^{\mathrm{E} 2}=2.6733 \times 10^{3} \mathrm{~s}^{-1}\left(E_{j}-E_{i}\right)^{5} S^{\mathrm{E} 2}(i, j)$

and

$g_{j} A_{j i}^{\mathrm{M} 1}=3.5644 \times 10^{4} \mathrm{~s}^{-1}\left(E_{j}-E_{i}\right)^{3} S^{\mathrm{M} 1}(i, j) ;$

electric octopole (E3) and magnetic quadrupole (M2)

$g_{j} A_{j i}^{\mathrm{E} 3}=1.2050 \times 10^{-3} \mathrm{~s}^{-1}\left(E_{j}-E_{i}\right)^{7} S^{\mathrm{E} 3}(i, j)$

and

$g_{j} A_{j i}^{\mathrm{M} 2}=2.3727 \times 10^{-2} \mathrm{~s}^{-1}\left(E_{j}-E_{i}\right)^{5} S^{\mathrm{M} 2}(i, j)$.

In approximations like BP one should be careful with the radiative magnetic operators about terms of order $\alpha^{2}$, in particular in $O^{\mathrm{M} 1}$, which cannot connect different configurations by its leading term $l(\mathrm{p})+2 s(\mathrm{p})$ because the (tensor-) radial portion reduces to trivial 1; SUPERSTRUCTURE does add both 1-body and 2-body contributions of Breit-Pauli order to M1 but not to M2.

\section{Computation}

BPRM calculations span several stages of computation (Berrington et al. 1995). We take radial Fe XVIII wavefuntions from SUPERSTRUCTURE (Eissner et al. 1974) as input to STG1 to compute Slater, magnetic and multipole integrals - obtained with Thomas-Fermi scaling parameters $\lambda_{n l}$ of $1.3835,1.1506,1.0837,1.0564,1.0175,1.0390$ for orbitals $n l=1 \mathrm{~s}, 2 \mathrm{~s}, 2 \mathrm{p} . .3 \mathrm{~d}$, which leads to excited levels $2 \mathrm{~s}^{2} 2 \mathrm{p}^{5}{ }^{2} \mathrm{P}_{1 / 2}^{\mathrm{o}}$ and $2 \mathrm{~s} 2 \mathrm{p}^{62} \mathrm{~S}_{1 / 2}$ at 0.9403 and 9.8092 Rydbergs above the ground state $2 \mathrm{~s}^{2} 2 \mathrm{p}^{52} \mathrm{P}_{3 / 2}^{\mathrm{o}}$ (while including correlation terms from 6 configurations: $2 s^{2} 2 p^{4} 3 l$ and $2 \mathrm{~s} 2 \mathrm{p}^{5} 3 l-$ " $1 \mathrm{~s}^{2}$ " suppressed for brevity); the excitation energies above the ground state compare with NIST data of 0.93477 and 9.7023 Ry respectively. Other excited levels of Fe XVIII lie too high to play a role as parent for any Fe XVII bound states (50 Ry separating M- from L-shell: level $2 \mathrm{~s}^{2} 2 \mathrm{p}^{4} 3 \mathrm{~s}{ }^{4} \mathrm{P}_{5 / 2}$ at 57.01 Ry), and therefore need not be considered for radiative calculations. Radial integrals for the partial wave expansion in Eq. (1) are specified for orbitals $0 \leq \ell \leq 9$ as a basis of NRANG2 = 11 "continuum" functions - sufficient for bound electrons with $n<10$ at a radius RA $=2.3750$ (Bohr radii $\left.a_{0}\right)$ of the $R$-matrix box.

Along with the target description STG2 input specifies which collisional Fe XVII symmetries $L S$ eventually contribute to $0 \leq J \leq 7$ or 8 of even and odd parities, namely $0 \leq L \leq 7$ or 8 , and multiplicities $(2 S+1)=1,3$. The second term in Eq. (1), on bound state correlation functions, is specified to include all possible $(N+1)$-particle configurations from a vacant $2 \mathrm{~s}$ shell to maximum occupancies $2 \mathrm{~s}^{2}, 2 \mathrm{p}^{6}, 3 \mathrm{~s}^{2}, 3 \mathrm{p}^{2}$, and $3 \mathrm{~d}^{2}$.

Stage RECUPD transforms to collisional symmetries $J \leq 7$ or 8 in a pair-coupling representation, and the (e + ion) Hamiltonian $R$-matrices for each total $J \pi$ are diagonalized in STGH employing observed target energies.

In STGB fine structure bound levels are found through the poles in the $(\mathrm{e}+$ ion) Hamiltonian, searched over a fine mesh of effective quantum number $v: \Delta v=0.001$. The mesh is orders of magnitude finer than the typical $\Delta v=0.01$ required to find $L S$ energy terms. Intermediate coupling calculations therefore need orders of magnitude more CPU time than calculations in $L S$ coupling. Since the fine structure components of higher excited states are more densely packed, a mesh finer than $\Delta v=0.001$ is essential to avoid missing any levels.

Spectroscopically identifying a large number of fine structure levels poses a major challenge, as the BP Hamiltonian is labelled only by the total angular momentum and parity, i.e. by $J \pi$, which is incomplete for unique identification. Complete identification of levels is needed for various spectral diagnostics and spectrocopic applications in a lab. A new procedure has been developed and encoded in the program PRCBPID to identify these levels by a complete set of quantum numbers through analysis of coupled channels in the CC expansion (Nahar \& Pradhan 2000). This procedure generally yields unambiguous level identification for most levels. However, for mixed levels where the identification is to some extent arbitrary, we assign levels in descending multiplicity $(2 S+1)$ and total angular orbital momentum $L$. The full spectroscopic designation reads $C_{\mathrm{t}}\left(S_{\mathrm{t}} L_{\mathrm{t}} \pi_{\mathrm{t}}\right) J_{\mathrm{t}} n l J(S L) \pi$, where $C_{\mathrm{t}}, S_{\mathrm{t}} L_{\mathrm{t}} \pi_{\mathrm{t}}, J_{\mathrm{t}}$ are the configuration, parent term and parity, and total angular momentum of target states, $n l$ are the principal and orbital quantum numbers of the outer or valence electron, and $J$ and $S L \pi$ are the total angular momentum, term and parity of the $(N+1)$-electron system. The procedure also establishes a correspondence between the fine structure levels and their proper $L S$ terms, and enables completeness checks to be performed as exemplified below.

STGBB can compute radiative data for transitions of type E1 and E2; the code exploits methods developed by Seaton (1986) to evaluate the outer region ( $>\mathrm{RA}$ ) contributions to the radiative transition matrix elements. However, present work reports 
Table 1. Comparing effective quantum numbers $v_{0}$ of observed binding energies $E_{\mathrm{o}}$ with $v_{\mathrm{c}}$ computed in stage STGB of BPRM ( $v$ measured from respective Fe XVIII threshold $t$ ). Index $I_{J}$ counts levels within symmetry $J \pi$ in energy order, * indicating that level $J$ belongs to an incompletely observed multiplet.

\begin{tabular}{|c|c|c|c|c|c|c|c|}
\hline \multicolumn{2}{|l|}{ Level } & $J$ & $I_{J}$ & $E_{\mathrm{o}} / \mathrm{Ry}$ & $v_{\mathrm{o}}$ & $v_{\mathrm{c}}$ & \\
\hline 2s22p6 & ${ }^{1} \mathrm{~S}$ & 0 & 1 & 92.760 & 1.7651 & 1.7643 & \\
\hline $2 \mathrm{~s} 22 \mathrm{p} 5(2 \mathrm{P} * 3 / 2) 3 \mathrm{~s}$ & ${ }^{3} \mathrm{P}^{\mathrm{o}}$ & 2 & 1 & 39.463 & 2.7062 & 2.7063 & \\
\hline $2 \mathrm{~s} 22 \mathrm{p} 5(2 \mathrm{P} * 3 / 2) 3 \mathrm{~s}$ & ${ }^{3} \mathrm{P}^{\mathrm{o}}$ & 1 & 1 & & 2.7110 & 2.7111 & \\
\hline $2 \mathrm{~s} 22 \mathrm{p} 6(2 \mathrm{P} * 1 / 2) 3 \mathrm{~s}$ & ${ }^{3} \mathrm{P}^{\mathrm{o}}$ & 0 & 1 & 3.533 & 2.7060 & 2.7064 & \\
\hline $2 \mathrm{~s} 22 \mathrm{p} 6(2 \mathrm{P} * 1 / 2) 3 \mathrm{~s}$ & ${ }^{1} \mathrm{P}^{\mathrm{o}}$ & 1 & 2 & 8.446 & 2.7090 & 2.7095 & \\
\hline $2 \mathrm{~s} 22 \mathrm{p} 53 \mathrm{p}$ & ${ }^{3} \mathrm{~S}$ & 1 & 1 & 37.238 & 2.7858 & 2.7858 & \\
\hline $2 \mathrm{~s} 22 \mathrm{p} 53 \mathrm{p}$ & ${ }^{3} \mathrm{D}$ & 3 & 1 & & 2.8000 & 2.8001 & \\
\hline $2 \mathrm{~s} 22 \mathrm{p} 53 \mathrm{p}$ & ${ }^{3} \mathrm{D}$ & 2 & 1 & .981 & 2.7955 & 2.7958 & \\
\hline $2 s 22$ & ${ }^{3} \mathrm{D}$ & 1 & 3 & & 2.7937 & 2.7945 & \\
\hline $2 \mathrm{~s} 22$ & ${ }^{1} \mathrm{P}$ & 1 & 2 & 36.780 & 2.8031 & 2.8034 & \\
\hline $2 \mathrm{~s} 22$ & ${ }^{3} \mathrm{P}$ & 2 & 2 & & 2.8082 & 2.8085 & \\
\hline $2 \mathrm{~s} 2$ & ${ }^{3} \mathrm{P}$ & 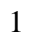 & 4 & & 2.8028 & 2.8034 & \\
\hline & ${ }^{3} \mathrm{P}$ & 0 & 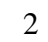 & & 2.8238 & 2.8246 & \\
\hline $2 s 22$ & ${ }^{1} \mathrm{D}$ & 2 & 3 & & 2.8039 & 2.8046 & \\
\hline & ${ }^{1} \mathrm{~S}$ & 0 & 3 & & 2.8410 & 2.8437 & \\
\hline & ${ }^{3} \mathrm{P}^{\mathrm{o}}$ & 2 & 2 & & 2.9301 & 2.9324 & \\
\hline $3 \mathrm{~d}$ & ${ }^{3} \mathrm{P}^{\mathrm{o}}$ & 1 & 3 & 3.778 & 2.9250 & 2.9260 & \\
\hline $2 \mathrm{~s} 2$ & ${ }^{3} \mathrm{P}^{\mathrm{o}}$ & 0 & 2 & & 2.9214 & 2.9226 & \\
\hline $2 \mathrm{~s} 2$ & ${ }^{3} \mathrm{~F}^{\circ}$ & 4 & 1 & & 2.9303 & 2.9 & \\
\hline & ${ }^{3} \mathrm{~F}^{\mathrm{o}}$ & 3 & 1 & & 2.9329 & 2.9346 & \\
\hline $2 \mathrm{~s} 2$ & ${ }^{3} \mathrm{~F}^{o}$ & 2 & 4 & & 2.9325 & 2.9346 & \\
\hline $2 \mathrm{~s} 2$ & ${ }^{1} \mathrm{D}^{\mathrm{o}}$ & 2 & 3 & 72 & 2.9384 & 2.9403 & \\
\hline $2 s 22$ & ${ }^{3} \mathrm{D}^{\circ}$ & 3 & ? & & 2.9419 & 2.9444 & \\
\hline & ${ }^{3} \mathrm{D}^{\circ}$ & 2 & J & & & 2.9 & \\
\hline & ${ }^{3} \mathrm{D}^{\mathrm{o}}$ & 1 & 4 & & 2.9570 & 2.9595 & \\
\hline $2 \mathrm{~s} 2$ & ${ }^{1} \mathrm{~F}^{\mathrm{o}}$ & 3 & 3 & & 2.9373 & 2.9397 & \\
\hline $2 \mathrm{~s} 2$ & ${ }^{1} \mathrm{P}^{\mathrm{o}}$ & 1 & 5 & & 2.9591 & 2.9525 & \\
\hline & ${ }^{3} \mathrm{P}^{\mathrm{o}}$ & 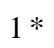 & 6 & & 2.8000 & 2.8 & \\
\hline & ${ }^{1} \mathrm{P}^{\mathrm{o}}$ & 1 & 7 & & 2.8124 & 2.8171 & \\
\hline$(2 \mathrm{P} * 3 / 2) 4 \mathrm{~s}$ & ${ }^{3} \mathrm{P}^{\mathrm{o}}$ & $1 *$ & 8 & 99 & 3.7187 & 3.7209 & \\
\hline $2 \mathrm{~s} 22 \mathrm{p} 5(2 \mathrm{P} * 1 / 2) 4 \mathrm{~s}$ & ${ }^{1} \mathrm{P}^{\mathrm{o}}$ & 1 & 9 & 14 & 3.7142 & 3.7188 & \\
\hline $2 \mathrm{~s} 22 \mathrm{p} 54 \mathrm{~d}$ & ${ }^{3} \mathrm{P}^{\mathrm{o}}$ & $1 *$ & 10 & & 3.9205 & 3.9283 & \\
\hline & ${ }^{3} \mathrm{D}^{\mathrm{o}}$ & $1 *$ & & & & & \\
\hline $2 \mathrm{~s} 2$ & ${ }^{1} \mathrm{P}^{\mathrm{o}}$ & 1 & 12 & & 3.9498 & 3.9540 & \\
\hline $2 \mathrm{~s} 2$ & ${ }^{3} \mathrm{P}^{\mathrm{o}}$ & $1 *$ & 13 & 60 & 4.7222 & 4.7201 & \\
\hline $2 \mathrm{~s} 22 \mathrm{p} 5(2 \mathrm{P} * 1 / 2) 5 \mathrm{~s}$ & ${ }^{1} \mathrm{P}^{\mathrm{o}}$ & 1 & 14 & & 4.7228 & 4.7173 & \\
\hline & ${ }^{3} \mathrm{P}^{\mathrm{o}}$ & $1 *$ & 15 & & 4.9030 & 4.9258 & \\
\hline $2 \mathrm{~s} 2$ & ${ }^{3} \mathrm{D}^{\mathrm{o}}$ & $1 *$ & 16 & 76 & 4.9539 & 4.9610 & \\
\hline $2 \mathrm{~s} 2$ & ${ }^{1} \mathrm{P}^{\mathrm{o}}$ & 1 & 17 & 10 & 4.9395 & 4.9484 & \\
\hline & ${ }^{3} \mathrm{P}^{\mathrm{o}}$ & $1 *$ & 18 & 10.236 & 3.8072 & 3.8142 & \\
\hline $2 \mathrm{~s} 2 \mathrm{l}$ & ${ }^{1} \mathrm{P}^{\mathrm{o}}$ & 1 & 19 & & 3.8212 & 3.8235 & \\
\hline & ${ }^{3} \mathrm{P}^{\mathrm{o}}$ & $1 *$ & 20 & & 5.7380 & 5.7196 & \\
\hline $2 \mathrm{P} * 3 / 2) 6 \mathrm{~d}$ & ${ }^{3} \mathrm{P}^{\mathrm{o}}$ & $1 *$ & 22 & 8.1488 & 5.9555 & 5.9547 & \\
\hline $2 \mathrm{~s} 22 \mathrm{p} 5(2 \mathrm{P} * 1 / 2) 6 \mathrm{~d}$ & ${ }^{1} \mathrm{P}^{\mathrm{o}}$ & $1 *$ & 24 & 7.2558 & 5.9401 & 5.9417 & \\
\hline $2 \mathrm{~s} 22 \mathrm{p} 5(2 \mathrm{P} * 3 / 2) 7 \mathrm{~s}$ & ${ }^{3} \mathrm{P}^{\mathrm{o}}$ & $1 *$ & 25 & 6.3810 & 6.7298 & 6.7220 & \\
\hline $2 \mathrm{~s} 22 \mathrm{p} 5(2 \mathrm{P} * 3 / 2) 7 \mathrm{~d}$ & ${ }^{3} \mathrm{P}^{\mathrm{o}}$ & $1 *$ & 26 & 5.9709 & 6.9571 & 6.9240 & \\
\hline $2 \mathrm{~s} 22 \mathrm{p} 5(2 \mathrm{P} * 1 / 2) 7 \mathrm{~d}$ & ${ }^{1} \mathrm{P}^{\mathrm{o}}$ & $1 *$ & 29 & 5.0232 & 6.9647 & 6.9422 & \\
\hline $2 \mathrm{~s} 22 \mathrm{p} 5(2 \mathrm{P} * 3 / 2) 8 \mathrm{~d}$ & ${ }^{3} \mathrm{P}^{\mathrm{o}}$ & $1 *$ & 31 & 4.4582 & 8.0514 & 7.9267 & \\
\hline $2 \mathrm{~s} 22 \mathrm{p} 5(2 \mathrm{P} * 1 / 2) 8 \mathrm{~d}$ & ${ }^{1} \mathrm{P}^{\mathrm{o}}$ & $1 *$ & 35 & 3.6016 & 7.9817 & 7.9397 & \\
\hline $2 \mathrm{~s} 2 \mathrm{p} 65 \mathrm{p}$ & ${ }^{3} \mathrm{P}^{\mathrm{o}}$ & $1 *$ & 42 & 2.7450 & 4.8185 & 4.8141 & \\
\hline $2 \mathrm{~s} 2 \mathrm{p} 65 \mathrm{p}$ & ${ }^{1} \mathrm{P}^{\mathrm{o}}$ & 1 & 43 & 2.7450 & 4.8185 & 4.8250 & \\
\hline
\end{tabular}

n. b. $E_{\mathrm{t}} / \mathrm{Ry}=0.0,0.9348,9.7023$ [M-shell: $57.08, \ldots 74.14$, N-shell: $77.05, \ldots 91.36$, O-shell: 85.71, .. 98.66] only E1 transitions from STGBB. Results for other types of transitions are obtained from SUPERSTRUCTURE, first optimizing the energy functional over the lowest 49 terms $L S$ (Chen et al. 2002, CPE02). They arise from 15 configurations: $2 \mathrm{~s}^{2} 2 \mathrm{p}^{6}$, $2 \mathrm{~s}^{2} 2 \mathrm{p}^{5} 3 l, 2 \mathrm{~s}^{2} 2 \mathrm{p}^{5} 4 l, 2 \mathrm{~s}^{1} 2 \mathrm{p}^{6} 3 l$, and $2 \mathrm{~s}^{1} 2 \mathrm{p}^{6} 4 l$; the scaling parameters $\lambda_{n l}$ for the Thomas-Fermi-Dirac-Amaldi type potential of orbital $n l$ are listed in Table 1 of CPE02. Much effort was devoted to choosing scaling parameters to optimise the target wavefunctions of the M-shell levels. The primary criteria in this selection are agreement with the observed values for (a) level energies and fine structure splittings within the lowest terms $L S$, and (b) $f$-values for a number of the low lying dipole allowed transitions. Another practical criterion is that the calculated coefficients $A$ should be variationally stable.

Experimental energy level differences are employed in the calculation of all types of transition probabilities wherever available, ensuring proper phase space (or energy) factors for $f$ or $A$; only a small number of Fe XVII levels are spectroscopically observed though.

In addition to over 26000 electric dipole transitions we have computed $A^{\mathrm{E} 2}, A^{\mathrm{M} 1}, A^{\mathrm{E} 3}$ and $A^{\mathrm{M} 2}$ for 2312 transitions among the first 89 levels, about half of these forbidden transition probabilities larger than $10^{3} \mathrm{~s}^{-1}$. Selected transitions (Table 7) are compared with various other calculations. Results by Safronova et al. (2002, private communication) are included for comparison.

\section{Results}

We first describe the BPRM calculations for the energy levels and E1 dipole and intercombination transitions in Fe XVII and then discuss higher multipole order radiation.

\subsection{Fine structure levels}

A total of 490 bound fine structure energy levels of Fe XVII are obtained from interacting channels, or Rydberg series

$E=E_{\mathrm{t}}-\frac{z^{2}}{v^{2}}, \quad v=n-\mu_{l \pm 1 / 2}(t)$

with series limits $E_{\mathrm{t}}$ at the $3 \mathrm{Fe}$ XVIII "target" levels $2 \mathrm{~s}^{2} 2 \mathrm{p}^{52} \mathrm{P}_{3 / 2,1 / 2}^{\mathrm{o}}, 2 \mathrm{~s} 2 \mathrm{p}^{62} \mathrm{~S}_{1 / 2}$, for symmetries $0 \leq J \leq 7$ (both parities), implying series orbitals $0 \leq l \leq 8$. In intermediate coupling language we consider bound state levels of Fe XVII to angular momenta $L \leq 8$ of singlet and triplet symmetries (multiplets to high $L$ may thus be incomplete). Series are kept below effective quantum numbers $v=11$ measured from the target ground state. These are the most detailed close coupling calculations to date for the ion.

Table 1 tentatively matches the 52 spectroscopically observed levels from NIST with identified levels from our calculations (the level index $I_{J}$, in ascending energy order within a given symmetry $J \pi$, is most useful for reference in subsequent tables). Calculated effective quantum numbers $v_{\mathrm{c}}$ of the first 14 entries differ from observation within numerical uncertainties and errors due to neglect of two-body magnetic effects: typically $\Delta \mu \equiv \Delta v=0.0005$. The abrupt 
jump to 0.0027 at level 15 and typical values of 0.002 thereafter can be explained by the effect of M-shell target levels, for good reasons not included in the collision type work. For the lowest of the $105 \mathrm{M}$-shell levels a structure calculation yields 57.08 Ry above the Fe XVIII ground state; taking a binding energy of $92.76 \mathrm{Ry}$ for a $2 \mathrm{p}$ electron from the first entry in Table 1, a first quasi-degenerate state can be expected an adequate 35.68 Ry below the ground state. We see that such homologous states do not seriously affect the accuracy of our calculation. More important is that M-shell target configurations do not render it incomplete: a binding energy of about $40 \mathrm{Ry}$ for a 3 s electron taken from entries 2-5 of Table 1 would lead to true new levels beginning (60-40) Ry above the ionization limit. It is also worth noting that the quantum defects of these 4 entries are close enough for mere differences in the Coulomb environment, as s-electrons are not affected by ordinary spin-orbit coupling. Way down the table agreement deteriorates. While $\Delta \mu \approx 0.005$ may be considered acceptable and a value 0.01 needs some explanation, the attempts with the $7 \mathrm{~d}$ and more so $8 \mathrm{~d}$ levels are an utter failure, $8 \mathrm{~d}$ off by 0.13 and 0.04 , not to speak of a negative "observed" quantum defect of the second $8 \mathrm{~d}$ level. Such binding energies $E_{\mathrm{o}}$ are unlikely.

A complete set of energy levels to Fe XVII is available electronically. As in recent work (e.g. Nahar et al. 2000) the energies are presented in two formats: (i) in $L S$ term order for spectroscopy and completeness check, and (ii) in $J \pi$ order for practical applications. In the term format (i) the fine structure components of a $L S$ term are grouped together according to the same configuration, useful for spectroscopic diagnostics. It also checks for completeness of a set of energy levels that should belong to same $L S$ value and detects any missing level. Table 2a presents a sample of the table containing total sets of energies. The table contains partial sets of levels of Fe XVII. The columns specify the core $C_{\mathrm{t}}(S L \pi J)_{\mathrm{t}}$, the label $n l$ of the outer electron, total angular momentun $J$, energy in Rydbergs, the effective quantum number $v$ of the valence electron, and possible term designations $L S$ of the level. No effective quantum number is assigned to an equivalent electron state.

The top line of each set in Table 2 a gives the number Nlv of expected fine structure levels, spin and parity of the set $\left({ }^{2 S+1} L^{\pi}\right)$, and the values of $L$; the total angular quantum numbers $J$ associated with each $L$ are quoted parenthetically. This line is followed by the set of BPRM energy levels of same configurations. $\mathrm{Nlv}(\mathrm{c})$, at the end of the set, specifies the total number of $J$-levels obtained. If Nlv $=\operatorname{Nlv}(\mathrm{c})$ for a set, the calculated energy set is complete. Correspondence of couplings and completeness of levels is established by the program PRCBPID, which detects and prints missing levels. Each level of a set is further identified by all possible terms $L S$ (specified in the last column of the set). Multiple $L S$ terms are arranged according to multiplicity $(2 S+1)$ and $L$ as mentioned above. It may be noted that levels are grouped consistently, closely spaced in energies and effective quantum numbers, confirming proper designation of terms $L S$. The effective quantum number $(v)$ is expressed up to two significant digits after the decimal point; the main object is to show the consistency of fine structure components in the $L S$ grouping. Each level may be assigned to one or more $L S$ terms in the last column.
Table 2a. Sample table of fine structure energy levels of Fe XVII as sets of $L S$ term components; $C_{\mathrm{t}}$ is the core configuration, $v$ is the effective quantum number.

\begin{tabular}{|c|c|c|c|c|c|c|}
\hline$C_{\mathrm{t}}\left(S_{\mathrm{t}} L_{\mathrm{t}} \pi_{\mathrm{t}}\right)$ & $J_{\mathrm{t}}$ & & $J$ & $E /$ Ry & $v$ & $S L \pi$ \\
\hline \multicolumn{6}{|c|}{ Eqv electron/unidentified levels, parity: e } & \multirow{3}{*}{$1 \mathrm{~S} \mathrm{e}$} \\
\hline $2 \mathrm{~s} 22 \mathrm{p} 6$ & & & 0 & -92.8398 & & \\
\hline \multicolumn{6}{|c|}{$\mathrm{Nlv}(\mathrm{c})=1:$ set complete } & \\
\hline \multicolumn{7}{|c|}{$\mathrm{Nlv}=3,{ }^{3} L^{\mathrm{o}}: \mathrm{P}\left(\begin{array}{lll}2 & 1 & 0\end{array}\right)$} \\
\hline $2 \mathrm{~s} 22 \mathrm{p} 5(2 \mathrm{Po})$ & $3 / 2$ & $3 \mathrm{~s}$ & 2 & -39.4577 & 2.71 & $3 \mathrm{Po}$ \\
\hline $2 \mathrm{~s} 22 \mathrm{p} 5(2 \mathrm{Po})$ & $3 / 2$ & $3 \mathrm{~s}$ & 1 & -39.3187 & 2.71 & $3 \mathrm{Po}$ \\
\hline $2 \mathrm{~s} 22 \mathrm{p} 5(2 \mathrm{Po})$ & $1 / 2$ & $3 \mathrm{~s}$ & 0 & -38.5208 & 2.71 & $3 \mathrm{Po}$ \\
\hline \multicolumn{7}{|c|}{$\operatorname{Nlv}(\mathrm{c})=3:$ set complete } \\
\hline \multicolumn{7}{|c|}{$\mathrm{Nlv}=1,{ }^{1} L^{0}: \mathrm{P}(1)$} \\
\hline 2s22p5 (2Po) & $1 / 2$ & $3 \mathrm{~s}$ & 1 & -38.4324 & 2.71 & $1 \mathrm{Po}$ \\
\hline \multicolumn{7}{|c|}{$\operatorname{Nlv}(c)=1:$ set complete } \\
\hline \multicolumn{7}{|c|}{ 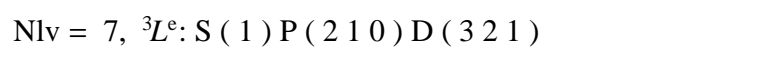 } \\
\hline $2 \mathrm{~s} 22 \mathrm{p} 5(2 \mathrm{Po})$ & $3 / 2$ & $3 p$ & 1 & -37.2397 & 2.79 & $3 \mathrm{SPD}$ e \\
\hline $2 \mathrm{~s} 22 \mathrm{p} 5(2 \mathrm{Po})$ & $1 / 2$ & $3 p$ & 2 & -36.9744 & 2.80 & $3 \mathrm{PD} \mathrm{e}$ \\
\hline $2 \mathrm{~s} 22 \mathrm{p} 5(2 \mathrm{Po})$ & $3 / 2$ & $3 p$ & 3 & -36.8541 & 2.80 & $3 \mathrm{De}$ \\
\hline $2 \mathrm{~s} 22 \mathrm{p} 5(2 \mathrm{Po}) 3$ & $3 / 2$ & $3 p$ & 2 & -36.6391 & 2.81 & $3 \mathrm{PD} \mathrm{e}$ \\
\hline $2 \mathrm{~s} 22 \mathrm{p} 5(2 \mathrm{Po})$ & $1 / 2$ & $3 p$ & 0 & -36.2221 & 2.82 & $3 \mathrm{Pe}$ \\
\hline $2 \mathrm{~s} 22 \mathrm{p} 5(2 \mathrm{Po})$ & $1 / 2$ & $3 p$ & 1 & -36.0724 & 2.79 & $3 \mathrm{SPD}$ e \\
\hline $2 \mathrm{~s} 22 \mathrm{p} 5(2 \mathrm{Po})$ & $3 / 2$ & $3 p$ & 1 & -35.8374 & 2.80 & $3 \mathrm{SPD}$ e \\
\hline \multicolumn{7}{|c|}{$\operatorname{Nlv}(\mathrm{c})=7$ : set complete } \\
\hline \multicolumn{7}{|c|}{$\mathrm{Nlv}=3,{ }^{1} L^{\mathrm{e}}: \mathrm{S}(0) \mathrm{P}(1) \mathrm{D}(2)$} \\
\hline $2 \mathrm{~s} 22 \mathrm{p} 5(2 \mathrm{Po})$ & $3 / 2$ & $3 p$ & 1 & -36.7729 & 2.80 & $1 \mathrm{Pe}$ \\
\hline $2 \mathrm{~s} 22 \mathrm{p} 5(2 \mathrm{Po})$ & $3 / 2$ & $3 p$ & 2 & -35.8059 & 2.80 & $1 \mathrm{De}$ \\
\hline 2s22p5 (2Po) & $1 / 2$ & $3 p$ & 0 & -34.8040 & 2.84 & $1 \mathrm{~S} \mathrm{e}$ \\
\hline \multicolumn{7}{|c|}{$\mathrm{Nlv}(\mathrm{c})=3$ : set complete } \\
\hline
\end{tabular}

For a multiple designation Hund's rule of decreasing multiplicity $(2 S+1)$ and $L$ is applied for further arrangement. One reason for specifying all possible terms is that the order of calculated and measured energy levels may not exactly match. Another reason is that although our term order arrangement may not apply to all cases for complex ions, it is nonetheless useful in order to establish completeness of fine structure components of a given $L S$ multiplet. 
Table 2b. Calculated Fe XVII fine structure levels, table not extended to symmetries other than $J \pi=0^{\mathrm{e}}$. This symmetry has Nlv $=20$ levels below $v=11$ for the core ground state series: 3 Rydberg series ( $v$ measured from the respective series limits, $E$ from the core ground state ${ }^{2} \mathrm{P}_{3 / 2}$, the first limit).

\begin{tabular}{|c|c|c|c|c|c|c|c|}
\hline \multirow[t]{2}{*}{$T$} & \multicolumn{3}{|c|}{ Level } & & \multirow{2}{*}{$\begin{array}{c}E / \mathrm{Ry} \\
\mathrm{J} \mathrm{pi}=\Theta \mathrm{e}\end{array}$} & \multirow[t]{2}{*}{$v$} & \multirow[t]{2}{*}{$S L \pi$} \\
\hline & & $\mathrm{Nlv}=$ & -20 & & & & \\
\hline 1 & $2 \mathrm{~s} 22 \mathrm{p} 6$ & & & 0 & $-9.28398 \mathrm{E}+1$ & & ${ }^{1} S^{e}$ \\
\hline 2 & $2 \mathrm{~s} 22 \mathrm{p} 5$ & $\left({ }^{2} \mathrm{P}_{3 / 2}^{\mathrm{o}}\right)$ & $3 p$ & 0 & $-3.62221 \mathrm{E}+1$ & 2.825 & ${ }^{3} \mathrm{P}^{\mathrm{e}}$ \\
\hline 3 & $2 \mathrm{~s} 22 \mathrm{p} 5$ & $\left({ }^{2} \mathrm{P}_{1 / 2}^{\mathrm{o}}\right)$ & $3 p$ & 0 & $-3.48040 \mathrm{E}+1$ & 2.844 & ${ }^{1} \mathrm{~S}^{\mathrm{e}}$ \\
\hline 4 & $2 \mathrm{~s} 2 \mathrm{p} 6$ & $\left({ }^{2} S_{1 / 2}\right)$ & $3 \mathrm{~s}$ & 0 & $-2.90350 \mathrm{E}+1$ & 2.731 & ${ }^{1} S^{\mathrm{e}}$ \\
\hline 5 & $2 \mathrm{~s} 22 \mathrm{p} 5$ & $\left({ }^{2} \mathrm{P}_{3 / 2}^{\mathrm{o}}\right)$ & $4 p$ & 0 & $-1.95296 \mathrm{E}+1$ & 3.847 & ${ }^{3} \mathrm{P}^{\mathrm{e}}$ \\
\hline 6 & $2 \mathrm{~s} 22 \mathrm{p} 5$ & $\left({ }^{2} \mathrm{P}_{1 / 2}^{\mathrm{o}}\right)$ & $4 p$ & 0 & $-1.87056 \mathrm{E}+1$ & 3826 & ${ }^{1} \mathrm{~S}^{\mathrm{e}}$ \\
\hline 7 & $2 \mathrm{~s} 22 \mathrm{p} 5$ & $\left({ }^{2} \mathrm{P}_{3 / 2}^{\mathrm{o}}\right)$ & $5 \mathrm{p}$ & 0 & $-1.22822 \mathrm{E}+1$ & 4.850 & ${ }^{3} \mathrm{P}^{\mathrm{e}}$ \\
\hline 8 & $2 \mathrm{~s} 22 \mathrm{p} 5$ & $\left({ }^{2} \mathrm{P}_{1 / 2}^{\mathrm{o}}\right)$ & $5 \mathrm{p}$ & 0 & $-1.14454 \mathrm{E}+1$ & 4.830 & ${ }^{1} \mathrm{~S}^{\mathrm{e}}$ \\
\hline 9 & $2 \mathrm{~s} 2 \mathrm{p} 6$ & $\left({ }^{2} S_{1 / 2}\right)$ & $4 \mathrm{~s}$ & 0 & $-1.10221 \mathrm{E}+1$ & 3.734 & ${ }^{1} S^{e}$ \\
\hline 10 & $2 \mathrm{~s} 22 \mathrm{p} 5$ & $\left({ }^{2} \mathrm{P}_{3 / 2}^{\mathrm{o}}\right)$ & $6 p$ & 0 & $-8.44845 \mathrm{E}+0$ & 5.849 & ${ }^{3} \mathrm{P}^{\mathrm{e}}$ \\
\hline 11 & $2 \mathrm{~s} 22 \mathrm{p} 5$ & $\left({ }^{2} \mathrm{P}_{1 / 2}^{\mathrm{o}}\right)$ & $6 \mathrm{p}$ & 0 & $-7.57469 \mathrm{E}+0$ & 5.828 & ${ }^{1} \mathrm{~S}^{\mathrm{e}}$ \\
\hline 12 & $2 \mathrm{~s} 22 \mathrm{p} 5$ & $\left({ }^{2} \mathrm{P}_{3 / 2}^{\mathrm{o}}\right)$ & $7 \mathrm{p}$ & 0 & $-6.15891 \mathrm{E}+0$ & 6.850 & ${ }^{3} \mathrm{P}^{\mathrm{e}}$ \\
\hline 13 & $2 \mathrm{~s} 22 \mathrm{p} 5$ & $\left({ }^{2} \mathrm{P}_{1 / 2}^{\mathrm{o}}\right)$ & $7 \mathrm{p}$ & 0 & $-5.26390 \mathrm{E}+0$ & 6.828 & ${ }^{1} S^{e}$ \\
\hline 14 & $2 \mathrm{~s} 22 \mathrm{p} 5$ & $\left({ }^{2} \mathrm{P}_{3 / 1}^{\mathrm{o}}\right)$ & $8 p$ & 0 & $-4.68712 \mathrm{E}+0$ & 7.852 & ${ }^{3} \mathrm{P}^{\mathrm{e}}$ \\
\hline 15 & $2 \mathrm{~s} 22 \mathrm{p} 5$ & $\left({ }^{2} \mathrm{P}_{1 / 2}^{\mathrm{o}}\right)$ & $8 \mathrm{p}$ & 0 & $-3.78258 \mathrm{E}+0$ & 27 & ${ }^{1} S^{e}$ \\
\hline 16 & $2 \mathrm{~s} 22 \mathrm{p} 5$ & $\left({ }^{2} \mathrm{P}_{3 / 2}^{\mathrm{o}}\right)$ & $9 p$ & 0 & $-3.68406 \mathrm{E}+0$ & 8.857 & ${ }^{3} \mathrm{P}^{\mathrm{e}}$ \\
\hline 17 & $2 \mathrm{~s} 2 \mathrm{p} 6$ & $\left({ }^{2} S_{1 / 2}\right)$ & $5 \mathrm{~s}$ & 0 & $-3.19987 \mathrm{E}+0$ & 4.733 & ${ }^{1} S^{e}$ \\
\hline 18 & $2 \mathrm{~s} 22 \mathrm{p} 5$ & $\left({ }^{2} \mathrm{P}_{3 / 2}^{\mathrm{o}}\right)$ & $10 p$ & 0 & $-2.97673 \mathrm{E}+0$ & 9.853 & ${ }^{3} \mathrm{P}^{\mathrm{e}}$ \\
\hline 19 & $2 \mathrm{~s} 22 \mathrm{p} 5$ & $\left({ }^{2} \mathrm{P}_{1 / 2}^{\mathrm{o}}\right)$ & $9 \mathrm{p}$ & 0 & $-2.76993 \mathrm{E}+0$ & 8.829 & ${ }^{1} \mathrm{~S}^{\mathrm{e}}$ \\
\hline 20 & $2 \mathrm{~s} 22 \mathrm{p} 5$ & $\left({ }^{2} \mathrm{P}_{3 / 2}^{\mathrm{o}}\right)$ & $11 \mathrm{p}$ & 0 & $-2.45262 \mathrm{E}+0$ & 10.855 & ${ }^{3} \mathrm{P}^{\mathrm{e}}$ \\
\hline
\end{tabular}

Format (ii) keeps the fine structure levels together as they emerge in the computational procedure: for a given symmetry $J \pi$ and in energy order as shown for $0^{\mathrm{e}}$ in Table $2 \mathrm{~b}$, which adds up to $\mathrm{Nlv}=20$ levels, after the self-explanatory header line. This format should be more convenient for easy implementation in astrophysical or other plasma modeling codes requiring large numbers of energy levels and associated transitions. Here of course we have a set small and transparent enough for assignment by hand rather than by the new code (note how different spin-orbit strength is reflected in the small difference between the quantum defects $\mu_{\mathrm{p}}$ of the two series here we are facing merely $\mathrm{p}_{3 / 2}$ with $t=1$ and $\mathrm{p}_{1 / 2}$ with $t=2$ because of $J=0)$. The levels are identified by core configuration $C_{\mathrm{t}}$ and level $(S L J)_{\mathrm{t}}$, the outer electron quantum number $n l$, total $J$, energy against the ionization threshold $t=1$, effective quantum number $v$ associated with the respective series limit $t$, and a term designation.

\subsection{Oscillator strengths for E1 transitions}

The 490 bound fine structure energy levels of Fe XVII give rise to 26222 dipole allowed and intercombination E1 transitions. The electronically available set contains calculated transition probabilities $A$, oscillator strengths $f$, and line strengths $S$ along with level energies.

A sample subset of transitions, generated by code STGBB, is presented in Table 3a. The first record of the raw output file FVALUE specifies the nuclear charge number $Z=26$, $N=9$ electrons in the core ion Fe XVIII, and processing directives (e.g. 0 - perturbative channel coupling between RA and $\infty$ disabled, $1-$ Buttle correction activated). The next two records, headers for the subsequent Fe XVII transition array data, identify this array as a pair $\left(\emptyset 2 J_{1} \pi_{1}, \emptyset 2 J_{2} \pi_{2}\right)$ of symmetries $(\pi=0$ for even and $=1$ for odd parity), here the electric dipole transition $J_{1}=0^{\mathrm{e}}-J_{2}=1^{\mathrm{o}}$. STGB had computed $N_{J_{i}}=20$ levels of the first symmetry (decoded in Table $2 \mathrm{~b}$ ), $N_{J_{k}}=47$ to the second, hence $20 \times 47$ subsequent records, each prefaced by a pair Ii and Ik of level indices (in energy order for the respective symmetry). Their bound state energies $E_{i}$ and $E_{k}$ below the Fe XVIII ground state are shown in Cols. 3 and 4 in reduced units $z^{2}$ Ry. The radiative result in the last three columns are the $g f$-values of the transition (see Eq. (8)) in length and velocity form and the coefficient $A$ for spontaneous emission (derived in the length form, see Eq. (9)). The signs of $g f$ are in accord with Eq. (8) and would reverse on swapping the order of symmetries $J \pi$. Complete spectroscopic identification of the transitions can be deduced from tables of type $2 \mathrm{~b}$. For the largest listed value, $2.301 \times 10^{13} / \mathrm{s}$ at $(\mathrm{Ii}, \mathrm{Ik}=1,5)$ and associated with excitation energy $60.846 \mathrm{Ry}$, Table $2 \mathrm{~b}$ verifies the initial level as the Fe XVII ground state; we have not presented the odd-parity $J=1$ section but can identify $\mathrm{I} i=5$ as a low lying state from Tables 1 or 6 as $2 \mathrm{~s}^{2} 2 \mathrm{p}^{5} 3 \mathrm{~d}^{1} \mathrm{P}_{1}^{\mathrm{o}}$; this transition reappears in Table 5 with energy-adjusted 2.28(13)/s.

Table $3 \mathrm{~b}$, dealing with the same transition array but taken from standard STGBB file stgbb. out makes interesting reading about the internal workings of the $R$-matrix method, as it details the contributions to the (unnormalized) radiative transition amplitude D. While the radial wave solutions associated with small principal quantum numbers like 2 or 3 lie entirely inside the $R$-matrix sphere with radius RA, they have most nodes outside at values $n \approx 10$. The composition of $\mathrm{D}$ therefore changes from dominant interior contributions DI to large outside portions DA as $n$ and $n^{\prime}$ increase. Perturbatively computed coupling contributions DP between the propagation range for DA and infinity equally increase, to stay only just small enough at $n=11$ to be neglected as in Table 2a (IPERT=0) and in fact most large scale calculations (whereas vital in collisional work!); unlike Buttle contributions DB, which compensate for the rigid logarithmic boundary condition at RA, their computation can be fairly time consuming. Especially transition $(15,29)=\left({ }^{2} \mathrm{P}_{1 / 2} 8 \mathrm{p} 0^{\mathrm{e}}-{ }^{2} \mathrm{P}_{1 / 2} 7 \mathrm{~d} 1^{\circ}\right)$ reveals a subtle balance among the constituents and between the amplitudes in length and velocity formulation.

The electronically available compilation of results $f, S$, and $A$ for the E1 transitions is formatted differently from Table $3 \mathrm{a}$ so as to match similar files for other ions (e.g. 


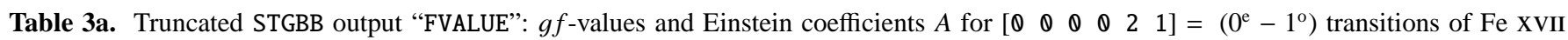
$[\mathrm{Z}=26$, core- $\mathrm{Ne} \mathrm{l}=9]$, as function of bound state energies $\operatorname{RE}\left(n_{1} l_{1} 0^{\mathrm{e}}\right)$ and $\operatorname{Re}\left(n_{2} l_{2} 1^{\mathrm{o}}\right)$ in units of $z^{2} \mathrm{Ry}, z=26-9$. The line strength column $S(\mathrm{E} 1)$ has been added by hand (see Eqs. (7), (8)) for the first transition array.

\begin{tabular}{|c|c|c|c|c|c|c|c|c|}
\hline \multicolumn{4}{|c|}{26} & IPERT $=0$ & \multicolumn{2}{|c|}{$\mathrm{AC}, \mathrm{IBUT}=1.0 \mathrm{E}-51$} & \multirow[t]{2}{*}{$06 / 25 / 01$} & \multirow[t]{2}{*}{$15: 06: 37$} \\
\hline & 0 & $\theta$ & 0 & $\theta$ & 1 & & & \\
\hline \multicolumn{2}{|c|}{20} & 47 & RE1 & RE2 & GFL -1 & E1 - GFV & \multirow{2}{*}{$\begin{array}{c}A(E 1) * S \\
9.396 E+11\end{array}$} & $\mathrm{~S}(\mathrm{E} 1)$ \\
\hline 1 & 1 & \multicolumn{2}{|c|}{$-3.212451 \mathrm{E}-1$} & $-1.360506 \mathrm{E}-1$ & $-1.225 \mathrm{E}-01$ & $-1.232 \mathrm{E}-01$ & & $6.866 \mathrm{E}-3$ \\
\hline 1 & 2 & \multicolumn{2}{|c|}{$-3.212451 \mathrm{E}-1$} & $-1.329843 \mathrm{E}-1$ & $-1.010 \mathrm{E}-01$ & $-1.020 \mathrm{E}-01$ & $8.005 E+11$ & $5.569 \mathrm{E}-3$ \\
\hline 1 & 3 & \multicolumn{2}{|c|}{$-3.212451 \mathrm{E}-1$} & $-1.167997 \mathrm{E}-1$ & $-8.149 \mathrm{E}-03$ & $3-8.015 E-03$ & $7.617 \mathrm{E}+10$ & $4.138 \mathrm{E}-4$ \\
\hline 1 & 4 & \multicolumn{2}{|c|}{$-3.212451 \mathrm{E}-1$} & $-1.141704 \mathrm{E}-1$ & $-6.222 \mathrm{E}-01$ & $1-5.940 \mathrm{E}-01$ & $5.967 E+12$ & $3.119 \mathrm{E}-2$ \\
\hline 1 & 5 & -3.212 & $2451 E-1$ & $-1.107050 \mathrm{E}-1$ & $-2.321 \mathrm{E}+00$ & $-2.214 \mathrm{E}+00$ & $2.301 \mathrm{E}+13$ & $1.144 \mathrm{E}-1$ \\
\hline 1 & 6 & -3.212 & $2451 E-1$ & $-9.354728 \mathrm{E}-2$ & $-3.511 \mathrm{E}-02$ & $2-3.404 \mathrm{E}-02$ & $4.070 \mathrm{E}+11$ & $1.601 \mathrm{E}-3$ \\
\hline 1 & 7 & -3.212 & $2451 \mathrm{E}-1$ & $-9.243291 \mathrm{E}-2$ & $-2.843 \mathrm{E}-01$ & $1-2.989 \mathrm{E}-01$ & $3.328 \mathrm{E}+12$ & $1.290 \mathrm{E}-2$ \\
\hline 1 & 8 & -3.212 & $2451 \mathrm{E}-1$ & I $-7.222739 \mathrm{E}-2$ & $-2.289 \mathrm{E}-02$ & $2-2.328 \mathrm{E}-02$ & $3.175 E+11$ & $9.542 \mathrm{E}-4$ \\
\hline 1 & 9 & -3.212 & $2451 \mathrm{E}-1$ & $-6.907663 \mathrm{E}-2$ & $-1.761 \mathrm{E}-02$ & $2-1.707 \mathrm{E}-02$ & $2.504 \mathrm{E}+11$ & $7.249 \mathrm{E}-4$ \\
\hline 1 & 10 & -3.212 & $2451 \mathrm{E}-1$ & $-6.480154 \mathrm{E}-2$ & $-3.289 \mathrm{E}-03$ & $3-3.310 \mathrm{E}-03$ & $4.837 \mathrm{E}+10$ & $1.331 \mathrm{E}-4$ \\
\hline 1 & 11 & -3.212 & $2451 \mathrm{E}-1$ & $-6.369437 \mathrm{E}-2$ & $-3.601 E-01$ & $1-3.275 E-01$ & $5.341 E+12$ & $1.451 \mathrm{E}-2$ \\
\hline 1 & 12 & -3.212 & $2451 \mathrm{E}-1$ & $-6.072860 \mathrm{E}-2$ & $-3.993 E-01$ & $1-3.613 E-01$ & $6.059 \mathrm{E}+12$ & $1.591 \mathrm{E}-2$ \\
\hline 1 & 13 & -3.2 & $2451 \mathrm{E}-1$ & $-4.488317 \mathrm{E}-2$ & $-1.004 \mathrm{E}-02$ & $2-1.027 \mathrm{E}-02$ & $1.715 \mathrm{E}+11$ & $3.771 \mathrm{E}-4$ \\
\hline 1 & 14 & -3.212 & $2451 \mathrm{E}-1$ & $-4.170278 \mathrm{E}-2$ & $-1.220 \mathrm{E}-02$ & $2-1.168 \mathrm{E}-02$ & $2.133 E+11$ & $4.530 \mathrm{E}-4$ \\
\hline 1 & 15 & -3.212 & $2451 \mathrm{E}-1$ & $-4.121385 \mathrm{E}-2$ & $-1.138 \mathrm{E}-03$ & $3-1.113 E-03$ & $1.996 \mathrm{E}+10$ & $4.219 \mathrm{E}-5$ \\
\hline 1 & 16 & -3.212 & $2451 \mathrm{E}-1$ & $-4.063208 \mathrm{E}-2$ & $-1.935 \mathrm{E}-01$ & $1-1.755 E-01$ & $3.407 \mathrm{E}+12$ & $7.158 \mathrm{E}-3$ \\
\hline 1 & 17 & -3.212 & $2451 \mathrm{E}-1$ & $-3.760452 E-2$ & $-1.488 \mathrm{E}-01$ & $1-1.349 E-01$ & $2.678 \mathrm{E}+12$ & $5.446 \mathrm{E}-3$ \\
\hline 1 & 18 & -3.21 & $2451 \mathrm{E}-1$ & $-3.522922 \mathrm{E}-2$ & $-1.075 \mathrm{E}-02$ & $2-1.194 \mathrm{E}-02$ & $1.967 \mathrm{E}+11$ & $3.902 \mathrm{E}-4$ \\
\hline 1 & 19 & -3.212 & $2451 \mathrm{E}-1$ & $-3.483027 \mathrm{E}-2$ & $-9.202 \mathrm{E}-02$ & $2-9.137 \mathrm{E}-02$ & $1.688 \mathrm{E}+12$ & $3.335 \mathrm{E}-3$ \\
\hline$\cdots$ & & & & & & & & \\
\hline 1 & 45 & -3.212 & $2451 \mathrm{E}-1$ & $-8.686647 \mathrm{E}-3$ & $-2.118 \mathrm{E}-04$ & $4-2.123 E-04$ & $4.628 \mathrm{E}+09$ & $7.034 \mathrm{E}-6$ \\
\hline 1 & 46 & -3.212 & $2451 \mathrm{E}-1$ & $-8.368791 \mathrm{E}-3$ & $-1.125 \mathrm{E}-04$ & $4-1.082 E-04$ & $2.464 \mathrm{E}+09$ & $3.733 \mathrm{E}-6$ \\
\hline 1 & 47 & -3.212 & $2451 \mathrm{E}-1$ & $-8.321573 E-3$ & $-1.418 \mathrm{E}-02$ & $2-1.271 \mathrm{E}-02$ & $3.105 \mathrm{E}+11$ & $4.704 \mathrm{E}-4$ \\
\hline 2 & 1 & -1.253 & $3358 \mathrm{E}-1$ & $-1.360506 \mathrm{E}-1$ & $1.012 \mathrm{E}-01$ & $19.828 \mathrm{E}-02$ & $7.797 \mathrm{E}+09$ & $9.804 \mathrm{E}-2$ \\
\hline 2 & 2 & -1.253 & $3358 \mathrm{E}-1$ & $-1.329843 \mathrm{E}-1$ & $2.878 \mathrm{E}-02$ & $2 \quad 2.541 \mathrm{E}-02$ & $1.129 \mathrm{E}+09$ & $3.906 \mathrm{E}-2$ \\
\hline 2 & 3 & -1.253 & $3358 \mathrm{E}-1$ & $-1.167997 \mathrm{E}-1$ & $-9.562 \mathrm{E}-03$ & $3-7.884 E-03$ & $1.558 \mathrm{E}+08$ & 1. $163 \mathrm{E}-2$ \\
\hline 2 & 4 & -1.253 & $3358 \mathrm{E}-1$ & $-1.141704 \mathrm{E}-1$ & $-2.041 \mathrm{E}-01$ & $1-2.001 \mathrm{E}-01$ & $5.689 \mathrm{E}+09$ & $1.898 \mathrm{E}-1$ \\
\hline & & & & & & & & \\
\hline 20 & 45 & -8.486 & $5569 \mathrm{E}-3$ & $3-8.686647 E-3$ & $7.494 \mathrm{E}-05$ & $5 \quad 5.519 \mathrm{E}-05$ & $2.012 \mathrm{E}+03$ & $3.822 \mathrm{E}-3$ \\
\hline 20 & 46 & -8.486 & $5569 E-3$ & $3-8.368791 \mathrm{E}-3$ & $-4.901 \mathrm{E}+00$ & $-4.929 \mathrm{E}+00$ & $1.520 \mathrm{E}+07$ & 4. $319 \mathrm{E}+2$ \\
\hline 20 & 47 & -8.486 & $5569 E-3$ & $3-8.321573 E-3$ & $-3.850 \mathrm{E}-01$ & $1-3.826 \mathrm{E}-01$ & $2.344 \mathrm{E}+06$ & $2.422 \mathrm{E}+1$ \\
\hline & 0 & 2 & 0 & 0 & 1 & & & \\
\hline & 45 & 19 & RE1 & RE2 & GFL -1 & E1 - GFV & $A(E 1) * S$ & \\
\hline 1 & 1 & -1.288 & $3567 E-1$ & $-1.332897 \mathrm{E}-1$ & $2.198 \mathrm{E}-03$ & $39.246 \mathrm{E}-04$ & $9.659 \mathrm{E}+06$ & \\
\hline 1 & 2 & -1.288 & $3567 E-1$ & $-1.170725 \mathrm{E}-1$ & $-1.226 \mathrm{E}-01$ & $1-1.213 E-01$ & $1.142 \mathrm{E}+10$ & \\
\hline 1 & 3 & -1.288 & $3567 \mathrm{E}-1$ & $-9.365835 \mathrm{E}-2$ & $-5.438 \mathrm{E}-02$ & $2-3.476 \mathrm{E}-02$ & $4.520 \mathrm{E}+10$ & \\
\hline & 0 & 0 & 0 & 0 & 0 & & & \\
\hline
\end{tabular}

for Fe XXI, Nahar 2000). Table 4 shows what the first section of Table $3 \mathrm{a}$ then looks like. The top line retains the charge number $Z$ but gives ionic $N_{\mathrm{el}}$ instead of target $N$; the second now assumes intermediate coupling, so $J=0^{\mathrm{e}}-J=1^{\mathrm{o}}$ suffices to specify the transition array $J_{i} \pi_{i}-J_{j} \pi_{j}$. The subsequent head line, starting with the number $N_{J i}$ and $N_{J j}$ of entries for the symmetry pair just as in Table $3 \mathrm{a}$, names the quantities tabulated for each of the $N_{J i} \times N_{J j}$ transitions. Again the first two columns specify a transition by level indices $i$ and $j$, while Rydberg energies of the level pair are no longer $z$-scaled. The value $g f_{\mathrm{L}}$ in Col. 5 is the quantity GFL of Table $3 \mathrm{a}$ (symmetrical in initial and final state: with statistical weight $g=J+1$ of the initial level, carrying the minus sign of $f=f^{\text {emission }}$ if the initial is the upper state!). It is derived from the primary quantity $S$ as of Eqs. (6), (7) given in the next column, hence subscript L for length formulation. The associated coefficient $A_{j i}$ of spontaneous emission trails in Col. 7.

Line strength results from BPRM are used to compute a set of transition probabilities $A$ and $f$-values for Fe XVII with observed energy separation in favour of the more uncertain calculated energies, exploiting that $S$ does not depend on level energies (the procedure is commonly employed and was first adopted in NIST compilations). The astrophysical models also in general use the observed transition energies for the relevant $f$ 
Table 3b. Truncated STGBB standard output: array $\left(0^{\mathrm{e}}-1^{\mathrm{o}}\right)$ of Fe XVII, build-up of the dipole transition amplitude D by the $R$-matrix code (L[ength] and V[elocity]).

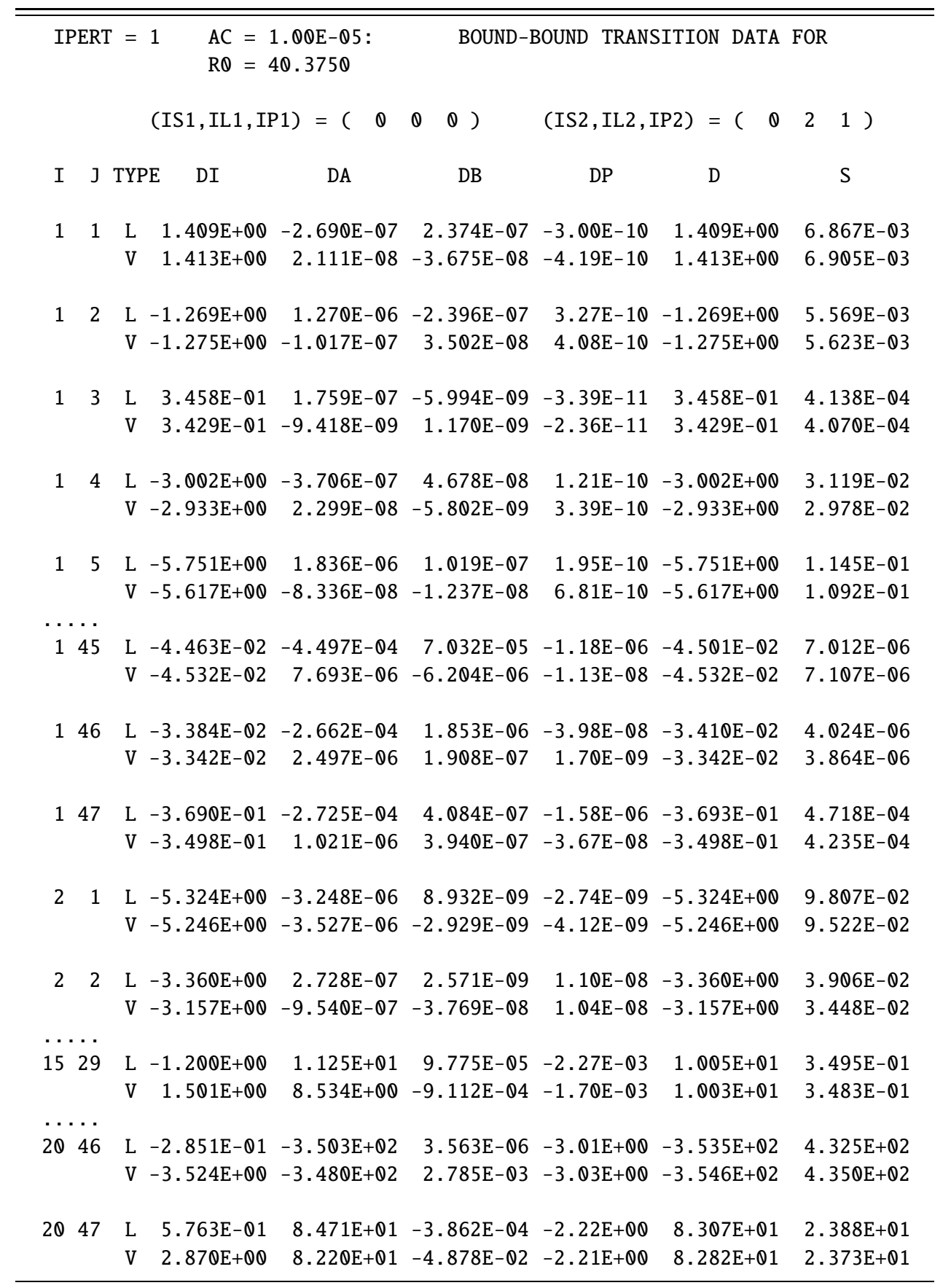

and $A$ data. They are more appropriate for comparison or spectral diagnostics.

Coefficients $A$ and $g f$-values have been reprocessed for all the allowed transitions $(\Delta J=0, \pm 1)$ among the observed levels. A partial set of these transitions is presented in Table 5. The set, also available electronically, comprises 342 transitions of Fe XVII. The reprocessed transitions are moreover ordered according to configuration $C$ and multiplet $L S$. This enables one to obtain the $f$-values for each multiplet $L S$ and check for completeness of the associated levels. Completeness however also depends on the observed set of fine structure levels since the transitions in the set correspond only to the observed levels (NIST). The $L S$ multiplets serve various comparisons with other calculations and experiment where fine structure transitions can not be resolved. The level index $I_{i}$ for each energy level in the table is given next to the $g$-value (e.g. $g_{i}: I_{i}$ ) for a easy pointer to the complete $f$-file.

BPRM coefficients $A$ are compared with other calculations in Table 6 , and with available NIST data. Safronova et al. (2001) obtained data of E1, E2, M1 and M2 type for 
Table 4. Sample set of $g f$-values and electric dipole transition probabilities $A$ for Fe XVII in $J \pi$ order. Notation $a \pm b$ means $a \times 10^{ \pm b}$.

\begin{tabular}{|c|c|c|c|c|c|c|}
\hline \multirow{2}{*}{\multicolumn{2}{|c|}{26}} & 10 & & & & \\
\hline & & $\begin{array}{ll}0 & 0\end{array}$ & 21 & & & \\
\hline 20 & 47 & $E_{i}(\mathrm{Ry})$ & $E_{j}(\mathrm{Ry})$ & $g f_{\mathrm{L}}$ & $S$ & $A_{j i} \cdot \mathrm{s}$ \\
\hline 1 & 1 & $-9.28398+1$ & $-3.93186+1$ & $-1.225-1$ & $6.866-3$ & $9.396 \mathrm{E}+1$ \\
\hline 1 & 12 & $-9.28398+1$ & $-3.84325+1$ & $-1.010-1$ & $5.569-3$ & $8.005 \mathrm{E}+1$ \\
\hline 1 & 3 & $-9.28398+1$ & $-3.37551+1$ & $-8.149-3$ & $4.138-4$ & $7.617 \mathrm{E}+1$ \\
\hline 1 & 14 & $-9.28398+1$ & $-3.29952+1$ & $-6.222-1$ & $3.119-2$ & $5.967 \mathrm{E}+12$ \\
\hline 1 & 5 & $-9.28398+1$ & $-3.19937+1$ & -2.321 & $1.144-1$ & $2.301 \mathrm{E}+1$ \\
\hline 1 & 16 & $-9.28398+1$ & $-2.70352+1$ & $-3.511-2$ & $1.601-3$ & $4.070 \mathrm{E}+1$ \\
\hline 1 & 17 & $-9.28398+1$ & $-2.67131+1$ & $-2.843-1$ & $1.290-2$ & $3.328 \mathrm{E}+12$ \\
\hline 1 & 18 & $-9.28398+1$ & $-2.08737+1$ & $-2.289-2$ & $9.542-4$ & $3.175 \mathrm{E}+11$ \\
\hline 1 & 19 & $-9.28398+1$ & $-1.99631+1$ & $-1.761-2$ & $7.249-4$ & $2.504 \mathrm{E}+1$ \\
\hline 1 & 10 & $-9.28398+1$ & $-1.87276+1$ & $-3.289-3$ & $1.331-4$ & $4.837 \mathrm{E}+10$ \\
\hline 1 & 11 & $-9.28398+1$ & $-1.84077+1$ & $-3.601-1$ & $1.451-2$ & $5.341 \mathrm{E}+12$ \\
\hline 1 & 12 & $-9.28398+1$ & $-1.75506+1$ & $-3.993-1$ & $1.591-2$ & $6.059 \mathrm{E}+12$ \\
\hline 1 & 13 & $-9.28398+1$ & $-1.29712+1$ & $-1.004-2$ & $3.771-4$ & $1.715 \mathrm{E}+1$ \\
\hline 1 & 14 & $-9.28398+1$ & $-1.20521+1$ & $-1.220-2$ & $4.530-4$ & $2.133 \mathrm{E}+11$ \\
\hline 1 & 15 & $-9.28398+1$ & $-1.19108+1$ & $-1.138-3$ & $4.219-5$ & $1.996 \mathrm{E}+10$ \\
\hline 1 & 16 & $-9.28398+1$ & $-1.17427+1$ & $-1.935-1$ & $7.158-3$ & $3.407 \mathrm{E}+12$ \\
\hline 1 & 17 & $-9.28398+1$ & $-1.08677+1$ & $-1.488-1$ & $5.446-3$ & $2.678 \mathrm{E}+12$ \\
\hline 1 & 18 & $-9.28398+1$ & $-1.01812+1$ & $-1.075-2$ & $3.902-4$ & $1.967 \mathrm{E}+11$ \\
\hline 1 & 19 & $-9.28398+1$ & $-1.00659+1$ & $-9.202-2$ & $3.335-3$ & $1.688 \mathrm{E}+12$ \\
\hline & $\cdot$ & $\cdots$ & 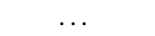 & 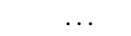 & $\cdots$ & 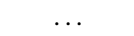 \\
\hline
\end{tabular}

transitions $2 l-3 l^{\prime}$ of Fe XVII using relativistic many-body perturbation theory (MBPT). Present results agree reasonably well yet with noticeable scatter compared to and also within (a)-(e), in particular for the decay of level 17 (for labels see Table 7): $2 s^{2} 2 p^{5} 3 d^{3} P_{1}^{o}-2 s^{2} 2 p^{6}{ }^{1} S_{0}$. Because of poorer consistency for intercombination transitions - as would happen when varying the strength of multiplet mixing - one might go for inclusion of all magnetic interactions among the valence electrons: after all there are 8 of them in this sequence, while BPRM ignores magnetic 2-body contributions (accounting only for interaction with the two closed-shell 1 s electrons). The result marked by $\ddagger$ looks encouraging - until one repeats the same short calculation without such terms: $8.27 \times 10^{10} / \mathrm{s}$ looks sobering besides the tabulated $8.89 \times 10^{10} / \mathrm{s}$. This way Bhatia \& Doschek's (1992) coefficient falls into place, leaving the Cornille et al. result - also from SUPERSTRUCTURE- the odd case out. The blanks for Cornille et al. in the last two transitions are not incidental, since they did not include configurations $2 \mathrm{~s}^{2} \mathrm{p}^{6} 3 l$ which become degenerate to $2 \mathrm{~s}^{2} 2 \mathrm{p}^{5} 3 l^{\prime}$ in the high $Z$ limit, according to Layzer's scaling laws (Layzer 1959), that it is essential to include all the configurations of the complex in order to correctly reproduce the terms of the $Z$-expansion of the non-relativistic energy. FS splitting of course is a different matter, and if 2-body magnetic interaction with the closed $\mathrm{K}$ shell is omitted the effective spin-orbit parameter $\zeta_{2 p}=0.620 \mathrm{Ry}\left(0.1484 \cdot Z^{4} / \mathrm{cm}\right)$ goes up to the "bare" value of $0.684 \mathrm{Ry}$ ( or $0.1644 \cdot Z^{4} / \mathrm{cm}$ ); for the effective spin-orbit parameter $\zeta$ to orbitals $l$, see Blume \& Watson (1962), Eissner et al. (1974), also Eq. (4). So much about a mute point of interpreting scatter. For electric dipole transitions the BPRM code in its present state is as good as other good approaches but readily delivering far larger data sets than anything to date.

Among forbidden transitions, discussed in the next section, there is one class for which it is obvious that one must draw very different conclusions, that is for transitions between levels of a FS multiplet: to start with, the splitting changes significantly on including 2-body FS contributions.

\subsection{Forbidden transitions $M 1, E 2$, and M2, E3}

We extend the behavioural study of computed radiative decay in Table 8 to a selection of forbidden transitions; a complete set will be published in electronic format, available from the CDS library for 2312 transitions between the 89 Fe XVII-levels. Table 8 along with Table 7 probes the quality of the target representations - especially term coupling, which is crucial in the collisional application (CPE02). Larger uncertainties are confined to intercombination lines, but there they can increase uncomfortably with higher radiative multipole type. Moreover the table assesses the influence of 2-body finestructure contributions neglected in the current BPRM work. Magnetic interaction between valence shell electrons is always present in the MCDF work with GRASP, activated for the SUPERSTRUCTURE column $\mathrm{SS}^{+}$but switched off in $\mathrm{SS}^{-}$: follow the trend from $\mathrm{SS}^{-}$via $\mathrm{SS}^{+}$to full relativistic MCDF.

At wave lengths of $10 \AA \approx 911 \AA / 100$ (hence $E_{i j}^{2}=10^{4} \mathrm{Ry}$ ) Eqs. (16), (17) versus (14), (15) suggest a close look at decay by electric octopole and magnetic quadrupole radiation for transitions with such a lowest path. We can indeed expect rates around $10^{6} / \mathrm{s}$, which would be competitive with E2 and M1 decay around $\mathrm{Fe}$ with $Z_{\mathrm{eff}} \approx 20$ along the $\mathrm{Ne}$-isoelectronic sequence, as the scaling laws show: inserting (7) for E $\lambda$ and (11) for $M \lambda$ into the line strength expression (6) yields scaling of $A$ as $Z^{8}$ for both E3 and M2 (and $Z^{6}$ for E2 and M1); for transitions within a principal shell $(\Delta n=0)$ though scaling of $\mathrm{E} \lambda$ drops by a factor of $Z^{2}$, and octopole transitions become negligible; we do not extend this discussion to intercombination transitions. The E3 results in Table 8 are most satisfactory and perfectly understood. To start with the two bottom entries, one of them apparently contradicting this statement, Table 7 identifies levels 87 and 89 as multiplet mixing companions with $J=3$ to terms $4 \mathrm{f}^{3} \mathrm{~F}$ and ${ }^{1} \mathrm{~F}$. Therefore the intercombination decay of 87 becomes rather sensitive to magnetic coupling, $A$ converging from right to left as much as one can reasonably expect when MCDF works with a slightly different target. This is borne out by 56, the only other troubling level for E3, as Table 7 places it marginally differently (unfortunately no experiment has yet decided). M2 is a different matter, a factor of 2.5 in the poor case $(18,1)$ difficult to reconcile with the lowest order radiative operator as adopted in SUPERSTRUCTURE. 
Table 5. Dipole allowed and intercombination transitions in Fe XVII. The calculated transition energies are replaced by observed energies. The $g: I$ indices refer to the statistical weight:energy level index in the raw data file. The notation $a(b)$ means $a \times 10^{b}$.

\begin{tabular}{|c|c|c|c|c|c|c|c|c|}
\hline$C_{i}$ & $C_{j}$ & $T_{i}$ & $T_{j}$ & $g_{i}: I_{i}$ & $g_{j}: I_{j}$ & $\lambda_{i j} / \AA$ & $f$ & $A \cdot \mathrm{s}$ \\
\hline $2 \mathrm{p} 6$ & $2 \mathrm{~s} 22 \mathrm{p} 53 \mathrm{~s}$ & ${ }^{1} S^{e}$ & ${ }^{3} \mathrm{P}^{\mathrm{o}}$ & $1: 1$ & $3: 1$ & 17.1 & $1.223(-1)$ & $9.35(11)$ \\
\hline $2 \mathrm{p} 6$ & $2 \mathrm{~s} 22 \mathrm{p} 63 \mathrm{~s}$ & ${ }^{1} \mathrm{~S}^{\mathrm{e}}$ & ${ }^{1} \mathrm{P}^{\mathrm{o}}$ & $1: 1$ & $3: 2$ & 16.8 & $1.008(-1)$ & $7.96(11)$ \\
\hline $2 \mathrm{p} 6$ & $2 \mathrm{~s} 22 \mathrm{p} 53 \mathrm{~d}$ & ${ }^{1} \mathrm{~S}^{\mathrm{e}}$ & ${ }^{3} \mathrm{P}^{\mathrm{o}}$ & $1: 1$ & $3: 3$ & 15.4 & $8.136(-3)$ & $7.58(10)$ \\
\hline $2 \mathrm{p} 6$ & $2 \mathrm{~s} 22 \mathrm{p} 53 \mathrm{~d}$ & ${ }^{1} S^{e}$ & ${ }^{3} \mathrm{D}^{0}$ & $1: 1$ & $3: 4$ & 15.3 & $6.208(-1)$ & $5.93(12)$ \\
\hline $2 \mathrm{p} 6$ & $2 \mathrm{~s} 22 \mathrm{p} 53 \mathrm{~d}$ & ${ }^{1} S^{e}$ & ${ }^{1} \mathrm{P}^{\mathrm{o}}$ & $1: 1$ & $3: 5$ & 15.0 & 2.314 & $2.28(13)$ \\
\hline $2 \mathrm{p} 6$ & $2 s 2 p 63 p$ & ${ }^{1} S^{e}$ & ${ }^{3} \mathrm{P}^{\mathrm{o}}$ & $1: 1$ & $3: 6$ & 13.9 & $3.501(-2)$ & $4.03(11)$ \\
\hline $2 \mathrm{p} 6$ & $2 \mathrm{~s} 2 \mathrm{p} 63 \mathrm{p}$ & ${ }^{1} S^{e}$ & ${ }^{1} \mathrm{P}^{\mathrm{o}}$ & $1: 1$ & $3: 7$ & 13.8 & $2.835(-1)$ & $3.30(12)$ \\
\hline $2 \mathrm{p} 6$ & $2 \mathrm{~s} 22 \mathrm{p} 54 \mathrm{~s}$ & ${ }^{1} S^{e}$ & ${ }^{3} \mathrm{P}^{\mathrm{o}}$ & $1: 1$ & $3: 8$ & 12.7 & $2.286(-2)$ & $3.16(11)$ \\
\hline $2 \mathrm{p} 6$ & $2 \mathrm{~s} 22 \mathrm{p} 54 \mathrm{~s}$ & ${ }^{1} \mathrm{~S}^{\mathrm{e}}$ & ${ }^{1} \mathrm{P}^{\mathrm{o}}$ & $1: 1$ & $3: 9$ & 12.5 & $1.758(-2)$ & $2.49(11)$ \\
\hline $2 \mathrm{p} 6$ & $2 \mathrm{~s} 22 \mathrm{p} 54 \mathrm{~d}$ & ${ }^{1} S^{e}$ & ${ }^{3} \mathrm{P}^{\mathrm{o}}$ & $1: 1$ & $3: 10$ & 12.3 & $3.281(-3)$ & $4.81(10)$ \\
\hline $2 \mathrm{p} 6$ & $2 \mathrm{~s} 22 \mathrm{p} 54 \mathrm{~d}$ & ${ }^{1} S^{e}$ & ${ }^{3} \mathrm{D}^{0}$ & $1: 1$ & $3: 11$ & 12.3 & $3.594(-1)$ & 5.31(12) \\
\hline $2 \mathrm{p} 6$ & $2 \mathrm{~s} 22 \mathrm{p} 54 \mathrm{~d}$ & ${ }^{1} \mathrm{~S}^{\mathrm{e}}$ & ${ }^{1} \mathrm{P}^{\mathrm{o}}$ & $1: 1$ & $3: 12$ & 12.1 & $3.987(-1)$ & $6.03(12)$ \\
\hline $2 \mathrm{p} 6$ & $2 \mathrm{~s} 22 \mathrm{p} 55 \mathrm{~s}$ & ${ }^{1} S^{e}$ & ${ }^{3} \mathrm{P}^{\mathrm{o}}$ & $1: 1$ & $3: 13$ & 11.4 & $1.003(-2)$ & 1.71(11) \\
\hline $2 \mathrm{p} 6$ & $2 \mathrm{~s} 22 \mathrm{p} 55 \mathrm{~s}$ & ${ }^{1} S^{e}$ & ${ }^{1} \mathrm{P}^{\mathrm{o}}$ & $1: 1$ & $3: 14$ & 11.3 & $1.219(-2)$ & $2.13(11)$ \\
\hline $2 \mathrm{p} 6$ & $2 \mathrm{~s} 22 \mathrm{p} 55 \mathrm{~d}$ & ${ }^{1} \mathrm{~S}^{\mathrm{e}}$ & ${ }^{3} \mathrm{P}^{\mathrm{o}}$ & $1: 1$ & $3: 15$ & 11.3 & $1.135(-3)$ & $1.98(10)$ \\
\hline $2 \mathrm{p} 6$ & $2 \mathrm{~s} 22 \mathrm{p} 55 \mathrm{~d}$ & ${ }^{1} \mathrm{~S}^{\mathrm{e}}$ & ${ }^{3} \mathrm{D}^{\mathrm{o}}$ & $1: 1$ & $3: 16$ & 11.3 & $1.932(-1)$ & $3.39(12)$ \\
\hline $2 \mathrm{p} 6$ & $2 \mathrm{~s} 22 \mathrm{p} 55 \mathrm{~d}$ & ${ }^{1} S^{e}$ & ${ }^{1} \mathrm{P}^{\mathrm{o}}$ & $1: 1$ & $3: 17$ & 11.1 & $1.486(-1)$ & $2.67(12)$ \\
\hline $2 \mathrm{p} 6$ & $2 s 2 p 64 p$ & ${ }^{1} \mathrm{~S}^{\mathrm{e}}$ & ${ }^{3} \mathrm{P}^{\mathrm{o}}$ & $1: 1$ & $3: 18$ & 11.0 & $1.073(-2)$ & $1.96(11)$ \\
\hline $2 \mathrm{p} 6$ & $2 \mathrm{~s} 2 \mathrm{p} 64 \mathrm{p}$ & ${ }^{1} S^{e}$ & ${ }^{1} \mathrm{P}^{\mathrm{o}}$ & $1: 1$ & $3: 19$ & 11.0 & $9.190(-2)$ & $1.68(12)$ \\
\hline $2 \mathrm{p} 53 \mathrm{~s}$ & $2 \mathrm{~s} 22 \mathrm{p} 53 \mathrm{p}$ & ${ }^{3} \mathrm{P}^{\mathrm{o}}$ & ${ }^{3} \mathrm{P}^{\mathrm{e}}$ & $3: 1$ & $1: 2$ & 296.0 & $3.354(-2)$ & $7.66(09)$ \\
\hline $2 \mathrm{p} 53 \mathrm{~s}$ & $2 \mathrm{~s} 22 \mathrm{p} 53 \mathrm{p}$ & ${ }^{3} \mathrm{P}^{\mathrm{o}}$ & ${ }^{3} \mathrm{P}^{\mathrm{e}}$ & $3: 1$ & $3: 4$ & 262.7 & $5.893(-5)$ & $5.70(06)$ \\
\hline $2 \mathrm{p} 53 \mathrm{~s}$ & $2 \mathrm{~s} 22 \mathrm{p} 53 \mathrm{p}$ & ${ }^{3} \mathrm{P}^{\mathrm{o}}$ & ${ }^{3} \mathrm{P}^{\mathrm{e}}$ & $5: 1$ & $3: 4$ & 252.5 & $4.985(-3)$ & $8.69(08)$ \\
\hline $2 \mathrm{p} 53 \mathrm{~s}$ & $2 \mathrm{~s} 22 \mathrm{p} 53 \mathrm{p}$ & ${ }^{3} \mathrm{P}^{\mathrm{o}}$ & ${ }^{3} \mathrm{P}^{\mathrm{e}}$ & $3: 1$ & $5: 2$ & 340.4 & $9.075(-2)$ & $3.13(09)$ \\
\hline $2 \mathrm{p} 53 \mathrm{~s}$ & $2 \mathrm{~s} 22 \mathrm{p} 53 \mathrm{p}$ & ${ }^{3} \mathrm{P}^{\mathrm{o}}$ & ${ }^{3} \mathrm{P}^{\mathrm{e}}$ & $5: 1$ & $5: 2$ & 323.5 & $6.913(-2)$ & 4.41(09) \\
\hline$L S$ & & ${ }^{3} \mathrm{P}^{\mathrm{o}}$ & ${ }^{3} \mathrm{P}^{\mathrm{e}}$ & 9 & 9 & & $8.959(-2)$ & 6.71(09) \\
\hline $2 \mathrm{p} 63 \mathrm{~s}$ & $2 \mathrm{~s} 22 \mathrm{p} 53 \mathrm{p}$ & ${ }^{1} \mathrm{P}^{\mathrm{o}}$ & ${ }^{3} \mathrm{P}^{\mathrm{e}}$ & $3: 2$ & $1: 2$ & 413.8 & $9.557(-3)$ & $1.12(09)$ \\
\hline $2 \mathrm{p} 63 \mathrm{~s}$ & $2 \mathrm{~s} 22 \mathrm{p} 53 \mathrm{p}$ & ${ }^{1} \mathrm{P}^{\mathrm{o}}$ & ${ }^{3} \mathrm{P}^{\mathrm{e}}$ & $3: 2$ & $3: 4$ & 351.6 & $4.162(-2)$ & $2.25(09)$ \\
\hline $2 \mathrm{p} 63 \mathrm{~s}$ & $2 \mathrm{~s} 22 \mathrm{p} 53 \mathrm{p}$ & ${ }^{1} \mathrm{P}^{\mathrm{o}}$ & ${ }^{3} \mathrm{P}^{\mathrm{e}}$ & $3: 2$ & $5: 2$ & 506.3 & $1.464(-3)$ & $2.29(07)$ \\
\hline $2 p 53 p$ & $2 \mathrm{~s} 22 \mathrm{p} 53 \mathrm{~d}$ & ${ }^{3} \mathrm{P}^{\mathrm{e}}$ & ${ }^{3} \mathrm{P}^{\mathrm{o}}$ & $1: 2$ & $3: 3$ & 369.5 & $9.560(-3)$ & $1.56(08)$ \\
\hline $2 p 53 p$ & $2 \mathrm{~s} 22 \mathrm{p} 53 \mathrm{~d}$ & ${ }^{3} \mathrm{P}^{\mathrm{e}}$ & ${ }^{3} \mathrm{P}^{\mathrm{o}}$ & $3: 4$ & $1: 2$ & 457.5 & $1.443(-3)$ & $1.38(08)$ \\
\hline $2 p 53 p$ & $2 \mathrm{~s} 22 \mathrm{p} 53 \mathrm{~d}$ & ${ }^{3} \mathrm{P}^{\mathrm{e}}$ & ${ }^{3} \mathrm{P}^{\mathrm{o}}$ & $3: 4$ & $3: 3$ & 439.0 & $1.262(-3)$ & 4.37(07) \\
\hline $2 \mathrm{p} 53 \mathrm{p}$ & $2 \mathrm{~s} 22 \mathrm{p} 53 \mathrm{~d}$ & ${ }^{3} \mathrm{P}^{\mathrm{e}}$ & ${ }^{3} \mathrm{P}^{\mathrm{o}}$ & $3: 4$ & $5: 2$ & 415.7 & $5.280(-4)$ & $1.22(07)$ \\
\hline $2 \mathrm{p} 53 \mathrm{p}$ & $2 \mathrm{~s} 22 \mathrm{p} 53 \mathrm{~d}$ & ${ }^{3} \mathrm{P}^{\mathrm{e}}$ & ${ }^{3} \mathrm{P}^{\mathrm{o}}$ & $5: 2$ & $3: 3$ & 317.7 & $9.904(-3)$ & $1.09(09)$ \\
\hline $2 \mathrm{p} 53 \mathrm{p}$ & $2 \mathrm{~s} 22 \mathrm{p} 53 \mathrm{~d}$ & ${ }^{3} \mathrm{P}^{\mathrm{e}}$ & ${ }^{3} \mathrm{P}^{\mathrm{o}}$ & $5: 2$ & $5: 2$ & 305.4 & $5.093(-2)$ & $3.64(09)$ \\
\hline$L S$ & & ${ }^{3} \mathrm{P}^{\mathrm{e}}$ & ${ }^{3} \mathrm{P}^{\mathrm{o}}$ & 9 & 9 & & $3.145(-2)$ & 1.64(09) \\
\hline $2 p 53 p$ & $2 \mathrm{~s} 22 \mathrm{p} 53 \mathrm{~d}$ & ${ }^{3} \mathrm{P}^{\mathrm{e}}$ & ${ }^{3} \mathrm{D}^{\mathrm{o}}$ & $1: 2$ & $3: 4$ & 285.5 & $2.019(-1)$ & $5.51(09)$ \\
\hline $2 \mathrm{p} 53 \mathrm{p}$ & $2 \mathrm{~s} 22 \mathrm{p} 53 \mathrm{~d}$ & ${ }^{3} \mathrm{P}^{\mathrm{e}}$ & ${ }^{3} \mathrm{D}^{0}$ & $3: 4$ & $3: 4$ & 325.2 & $2.756(-3)$ & $1.74(08)$ \\
\hline $2 \mathrm{p} 53 \mathrm{p}$ & $2 \mathrm{~s} 22 \mathrm{p} 53 \mathrm{~d}$ & ${ }^{3} \mathrm{P}^{\mathrm{e}}$ & ${ }^{3} \mathrm{D}^{\mathrm{o}}$ & $3: 4$ & $5: 5$ & 279.9 & $1.945(-1)$ & $9.93(09)$ \\
\hline $2 \mathrm{p} 53 \mathrm{p}$ & $2 \mathrm{~s} 22 \mathrm{p} 53 \mathrm{~d}$ & ${ }^{3} \mathrm{P}^{\mathrm{e}}$ & ${ }^{3} \mathrm{D}^{0}$ & $5: 2$ & $3: 4$ & 253.6 & $1.599(-5)$ & $2.76(06)$ \\
\hline $2 p 53 p$ & $2 \mathrm{~s} 22 \mathrm{p} 53 \mathrm{~d}$ & ${ }^{3} \mathrm{P}^{\mathrm{e}}$ & ${ }^{3} \mathrm{D}^{0}$ & $5: 2$ & $5: 5$ & 225.1 & $4.933(-3)$ & $6.49(08)$ \\
\hline $2 p 53 p$ & $2 \mathrm{~s} 22 \mathrm{p} 53 \mathrm{~d}$ & ${ }^{3} \mathrm{P}^{\mathrm{e}}$ & ${ }^{3} \mathrm{D}^{0}$ & $5: 2$ & $7: 2$ & 280.1 & $1.573(-1)$ & $9.55(09)$ \\
\hline$L S$ & & ${ }^{3} \mathrm{P}^{\mathrm{e}}$ & ${ }^{3} \mathrm{D}^{0}$ & 9 & 15 & & $1.887(-1)$ & $1.08(10)$ \\
\hline $2 p 53 p$ & $2 \mathrm{~s} 22 \mathrm{p} 53 \mathrm{~d}$ & ${ }^{3} \mathrm{P}^{\mathrm{e}}$ & ${ }^{1} \mathrm{P}^{\mathrm{o}}$ & $1: 2$ & $3: 5$ & 218.3 & $1.528(-2)$ & $7.13(08)$ \\
\hline $2 \mathrm{p} 53 \mathrm{p}$ & $2 \mathrm{~s} 22 \mathrm{p} 53 \mathrm{~d}$ & ${ }^{3} \mathrm{P}^{\mathrm{e}}$ & ${ }^{1} \mathrm{P}^{\mathrm{o}}$ & $3: 4$ & $3: 5$ & 240.8 & $2.555(-2)$ & 2.94(09) \\
\hline $2 p 53 p$ & $2 \mathrm{~s} 22 \mathrm{p} 53 \mathrm{~d}$ & ${ }^{3} \mathrm{P}^{\mathrm{e}}$ & ${ }^{1} \mathrm{P}^{\mathrm{o}}$ & $5: 2$ & $3: 5$ & 199.1 & $1.793(-4)$ & $5.02(07)$ \\
\hline $2 p 53 p$ & $2 s 2 p 63 p$ & ${ }^{3} \mathrm{P}^{\mathrm{e}}$ & ${ }^{3} \mathrm{P}^{\mathrm{o}}$ & $1: 2$ & $3: 6$ & 100.3 & $3.128(-2)$ & $6.91(09)$ \\
\hline $2 p 53 p$ & $2 s 2 p 63 p$ & ${ }^{3} \mathrm{P}^{\mathrm{e}}$ & ${ }^{3} \mathrm{P}^{\mathrm{o}}$ & $3: 4$ & $3: 6$ & 104.8 & $2.500(-3)$ & $1.52(09)$ \\
\hline $2 p 53 p$ & $2 s 2 p 63 p$ & ${ }^{3} \mathrm{P}^{\mathrm{e}}$ & ${ }^{3} \mathrm{P}^{\mathrm{o}}$ & $3: 4$ & $3: 6$ & 104.8 & $2.500(-3)$ & $1.52(09)$ \\
\hline $2 \mathrm{p} 53 \mathrm{p}$ & $2 \mathrm{~s} 2 \mathrm{p} 63 \mathrm{p}$ & ${ }^{3} \mathrm{P}^{\mathrm{e}}$ & ${ }^{3} \mathrm{P}^{\mathrm{o}}$ & $5: 2$ & $3: 6$ & 96.1 & $2.663(-3)$ & $3.21(09)$ \\
\hline$L S$ & & ${ }^{3} \mathrm{P}^{\mathrm{e}}$ & ${ }^{3} \mathrm{P}^{\mathrm{o}}$ & 9 & 9 & & $5.822(-3)$ & $3.94(09)$ \\
\hline
\end{tabular}


Table 6. Comparison of BPRM calculations for decay $A^{\mathrm{E} 1}(j, 1)$ to the Fe XVII ground state $C_{1} T_{1}=2 \mathrm{~s}^{2} 2 \mathrm{p}^{6} \mathrm{~S}_{0}$ with other work.

\begin{tabular}{|c|c|c|c|}
\hline \multirow[t]{2}{*}{$j:$} & \multirow[t]{2}{*}{$C_{j}$} & \multicolumn{2}{|r|}{$A\left(s^{-1}\right)$} \\
\hline & & BPRM & Others \\
\hline \multirow[t]{2}{*}{ 3: } & $2 \mathrm{~s}^{2} 2 \mathrm{p}^{5} 3 \mathrm{~s}{ }^{1} \mathrm{P}_{1}^{\mathrm{o}}$ & $7.96(11)$ & $8.28(11)^{a}, 8.01(11)^{b}, 7.75(11)^{c}$ \\
\hline & & & $8.38(11)^{d}, 8.30(11)^{e}, 9.40(11)^{\ddagger}$ \\
\hline \multirow[t]{2}{*}{ 5: } & $2 \mathrm{~s}^{2} 2 \mathrm{p}^{5} 3 \mathrm{~s}{ }^{3} \mathrm{P}_{1}^{\mathrm{o}}$ & $9.35(11)$ & $9.76(11)^{a}, 9.44(11)^{b}, 9.09(11)^{c}$ \\
\hline & & & $9.63(11)^{d}, 9.34(11)^{\mathrm{e}}, 8.00(11)^{\ddagger}$ \\
\hline \multirow[t]{2}{*}{ 17: } & $2 \mathrm{~s}^{2} 2 \mathrm{p}^{5} 3 \mathrm{~d}^{3} \mathrm{P}_{1}^{\mathrm{o}}$ & $7.58(10)$ & $9.19(10)^{a}, 8.27(10)^{b}, 7.77(10)^{c}$ \\
\hline & & & $9.42(10)^{d}, 9.00(10)^{e}, 8.89(10)^{\ddagger}$ \\
\hline \multirow[t]{2}{*}{ 23: } & $2 s^{2} 2 p^{5} 3 d^{3} D_{1}^{o}$ & $5.93(12)$ & $6.33(12)^{a}, 5.68(12)^{b}, 5.23(12)^{c}$ \\
\hline & & & $6.01(12)^{d}, 6.01(12)^{e}, 5.72(12)^{\ddagger}$ \\
\hline \multirow[t]{2}{*}{ 27: } & $2 \mathrm{~s}^{2} 2 \mathrm{p}^{5} 3 \mathrm{~d}^{1} \mathrm{P}_{1}^{\mathrm{o}}$ & $2.28(13)$ & $2.24(13)^{a}, 2.64(13)^{b}, 2.44(13)^{c}$ \\
\hline & & & $2.47(13)^{d}, 2.28(13)^{e}, 2.52(13)^{\ddagger}$ \\
\hline \multirow[t]{2}{*}{ 31: } & $2 \mathrm{~s} 2 \mathrm{p}^{6} 3 \mathrm{p} \quad{ }^{3} \mathrm{P}_{1}^{\mathrm{o}}$ & $4.03(11)$ & $4.51(11)^{a}, 3.66(11)^{b}$ \\
\hline & & & $4.12(11)^{d}, 3.40(11)^{e}, 3.52(11)^{\ddagger}$ \\
\hline \multirow[t]{2}{*}{ 33: } & $2 \mathrm{~s} 2 \mathrm{p}^{6} 3 \mathrm{p} \quad{ }^{1} \mathrm{P}_{1}^{\mathrm{o}}$ & $3.30(12)$ & $3.34(12)^{a}, 3.21(12)^{b}$ \\
\hline & & & $3.29(12)^{d}, 3.30(12)^{e}, 3.25(12)^{\ddagger}$ \\
\hline \multicolumn{4}{|c|}{${ }^{a}$ Safronova et al. (2001), ${ }^{b}$ Bhatia \& Doschek (1992), } \\
\hline \multicolumn{4}{|c|}{${ }^{c}$ Cornille et al. (1994), ${ }^{d}$ present MCDF, ${ }^{e}$ NIST, } \\
\hline & STRUCTU & $1 a t$ & netic FS-components. \\
\hline
\end{tabular}

For E2 vs. M1 the picture turns very varied as early as for $\Delta n \neq 0$ : distinguishing between intercombination transitions (with factors like $\alpha^{2} Z^{2}$ and $\alpha^{2} Z^{3}$ ) and direct transition becomes a more persistent companion. For direct transitions between main shells both $A$ scale as $Z^{6}$, the time coefficient favouring E2. Next come radiative BP corrections to M1 remembered from the classical case of $1 \mathrm{~s} 2 \mathrm{~s}^{3} \mathrm{~S}$ decay. We verified the Bhatia and Doschek entries, converting to $A$ without those corrections with the help of an expedient tool: SUPERSTRUCTURE prints both the full line strength $S^{\mathrm{M} 1}$ and BP-deficient $S_{0}^{\mathrm{M} 1}$. Then $A(9,1)$ drops to less than its tenth, from its $\mathrm{Ss}^{+}$result $3.31 \times 10^{3} \mathrm{~s}^{-1}-$ albeit only half what MCDF is telling: greater discrepancies are associated with differences between $\mathrm{SS}^{+}$and $\mathrm{SS}^{-}$results and rather crowded fields in Table 7 for the respective $J \pi$, so BP may be stretched beyond its limits. The trends for E2 type transitions look perfect.

For electric dipole transitions, both direct and spin-flip, Table 8 gives $A$ in velocity form as a second entry to the more firmly established length results, as a measure of good target description (with the proviso after Eq. (7)). They compare encouragingly for the EIE work.
Turning briefly towards astrophysical and laboratory implications from Table 8, apart from selected spontaneous emission coefficients for dipole-allowed transitions it gives results for magnetic dipole and electric quadrupole radiation - and some magnetic quadrupole and electric octopole transitions of the same magnitude of some $10^{6} \mathrm{~s}^{-1}$ : of course this high multipole decay mode can compete only for transitions with very short wave length, i.e. to the ground state. It may influence the modeling of line emissions. In astronomy and in laboratory photoionized plasmas the M2 decay from level 2 has long been observed as a prominent line. The population of level 2 is fed by cascading from $2 p^{5} 3 s, 2 p^{5} 3 p$, and $2 p^{5} 3 d$ and higher configurations. Accurate M2 transition probabilities are the key to modeling this line. Moreover it has important plasma diagnostics potential.

\section{Conclusions}

From large-scale state-of-the-art calculations in Breit-Pauli approximation we obtain energy levels with principal quantum number up to $n=10$ and radiative transition probabilities of Fe XVII. All levels have been identified in spectroscopic notation and checked for completeness. The set of results far exceeds the currently available experimental and theoretical data.

Radiative data for most electric dipole transions as well as level positions agree within $10 \%$ and in most cases far better with available theoretical and experimental work of quality. This indicates that for these highly charged ions higher order relativistic and QED effects omitted in the BPRM calculations may lead to an error not exceeding the estimated uncertainty.

We have obtained a consistent set of coefficients $A$ for E2 and M1 type transitions and compared our SUPERSTRUCTURE and MCDF calculations with other calculations in the literature. Most results for $A^{\mathrm{E} 2}$ and $A^{\mathrm{M} 1}$ lie well inside $20-30 \%$ of uncertainty. However, numerically very small coefficients can differ from $50 \%$ to a factor of two: M2 and in particular E3 results are highly sensitive to the physics included and numerics (e.g. cancellation effects and numerical instabilities). Large differences are found between the SUPERSTRUCTURE and MCDF calculations. Especially the magnetic quadrupole results are hard to assess, suggesting further study of this issue.

All data are available electronically. Part of the $f$-values have been reprocessed using available observed energies for better accuracy. The new results should be particularly useful for the analysis of X-ray and Extreme Ultraviolet spectra from astrophysical and laboratory sources where non-local thermodynamic equilibrium (NLTE) atomic models with many excited levels are needed.

Acknowledgements. This work was partially supported by U.S. National Science Foundation (AST-9870089) and the NASA ADP program; WE enjoyed part-support by Sonderforschungsbereich 392 of the German Research Council. The computational work was largely carried out on the Cray T94 and Cray SV1 at the Ohio Supercomputer Center in Columbus, Ohio. 
Table 7. The first 89 fine-structure $n=2,3$ and 4 levels included in the EIE calculation by Chen et al. 2003: comparison of calculated and observed energies in Rydbergs for Fe XVII; "obs" data are observed values from NIST; the entries "ss" (Ss"/ss': without/with inclusion of 2-body magnetic components) and the entries "MCDF" are from SUPERSTRUCTURE and GRASP calculations respectively.

\begin{tabular}{|c|c|c|c|c|c|c|c|}
\hline$i$ & $S L J$ & (jj) $J$ & obs & $\mathrm{SS}^{-}$ & $\mathrm{ss}^{+}$ & $\mathrm{MCDF}$ & BPRM \\
\hline 1 & $2 s^{2} 2 p^{6}{ }^{1} S_{0}$ & $(0,0) 0$ & 0.0 & 0.0 & 0.0 & 0.0 & 0.0 \\
\hline 2 & $2 s^{2} 2 p^{5} 3 s^{3} P_{2}^{o}$ & $(3 / 2,1 / 2)^{\circ} 2$ & 53.2965 & 53.3622 & 53.3666 & 53.1684 & 53.3821 \\
\hline 3 & $3 \mathrm{~s}^{1} \mathrm{P}_{1}^{\mathrm{o}}$ & $(3 / 2,1 / 2)^{\mathrm{o}} 1$ & 53.43 & 53.5044 & 53.5091 & 53.3100 & 53.5211 \\
\hline 4 & $3 \mathrm{~s}^{3} \mathrm{P}_{0}^{\mathrm{o}}$ & $(1 / 2,1 / 2)^{\circ} 0$ & 54.2268 & 54.2865 & 54.2865 & 54.0957 & 54.3190 \\
\hline 5 & $3 \mathrm{~s}^{3} \mathrm{P}_{1}^{\mathrm{o}}$ & $(1 / 2,1 / 2)^{\circ} 1$ & 54.3139 & 54.3791 & 54.3697 & 54.1851 & 54.4074 \\
\hline 6 & $3 p^{3} S_{1}$ & $(3 / 2,1 / 2) 1$ & 55.5217 & 55.5686 & 55.5735 & 55.3963 & 55.6001 \\
\hline 7 & $3 p^{3} D_{2}$ & $(3 / 2,1 / 2) 2$ & 55.7787 & 55.8397 & 55.8455 & 55.6606 & 55.8654 \\
\hline 8 & $3 p^{3} D_{3}$ & $(3 / 2,3 / 2) 3$ & 55.8974 & 55.9463 & 55.9494 & 55.7791 & 55.9857 \\
\hline 9 & $3 p^{1} \mathrm{P}_{1}$ & $(3 / 2,3 / 2) 1$ & 55.9804 & 56.0338 & 56.0404 & 55.8654 & 56.7674 \\
\hline 10 & $3 p^{3} P_{2}$ & $(3 / 2,3 / 2) 2$ & 56.1137 & 56.1597 & 56.1642 & 55.9950 & 56.2007 \\
\hline 11 & $3 \mathrm{p}^{3} \mathrm{P}_{0}$ & $(3 / 2,3 / 2) 0$ & 56.5155 & 56.5821 & 56.5809 & 56.4050 & 56.2221 \\
\hline 12 & $3 \mathrm{p}^{3} \mathrm{D}_{1}$ & $(1 / 2,1 / 2) 1$ & 56.6672 & 56.7288 & 56.7211 & 56.5495 & 56.0669 \\
\hline 13 & $3 \mathrm{p}^{3} \mathrm{P}_{1}$ & $(1 / 2,3 / 2) 1$ & 56.9060 & 56.9499 & 56.9420 & 56.7855 & 57.0024 \\
\hline 14 & $3 \mathrm{p}^{1} \mathrm{D}_{2}$ & $(1 / 2,3 / 2) 2$ & 56.9336 & 56.9817 & 56.9703 & 56.8135 & 57.0339 \\
\hline 15 & $3 \mathrm{p}^{1} \mathrm{~S}_{0}$ & $(1 / 2,1 / 2) 0$ & 57.8894 & 58.0639 & 58.0619 & 57.9308 & 58.0358 \\
\hline 16 & $3 d^{3} P_{0}^{o}$ & $(3 / 2,3 / 2)^{\circ} 0$ & 58.8982 & 58.9407 & 58.9578 & 58.7738 & 59.0057 \\
\hline 17 & $3 \mathrm{~d}^{3} \mathrm{P}_{1}^{\mathrm{o}}$ & $(3 / 2,3 / 2)^{\circ} 1$ & 58.981 & 59.0188 & 59.0289 & 58.8454 & 59.0846 \\
\hline 18 & $3 d^{3} P_{2}^{o}$ & $(3 / 2,5 / 2)^{\circ} 2$ & 59.0976 & 59.1651 & 59.1659 & 58.9826 & 59.2305 \\
\hline 19 & $3 d^{3} F_{4}^{o}$ & $(3 / 2,5 / 2)^{\circ} 4$ & 59.1041 & 59.1821 & 59.1799 & 58.9901 & 59.2435 \\
\hline 20 & $3 d^{3} F_{3}^{\circ}$ & $(3 / 2,3 / 2)^{0} 3$ & 59.1611 & 59.2240 & 59.2347 & 59.0498 & 59.2820 \\
\hline 21 & $3 d^{1} D_{2}^{\mathrm{o}}$ & $(3 / 2,3 / 2)^{\circ} 2$ & 59.2875 & 59.3513 & 59.3630 & 59.1797 & 59.4106 \\
\hline 22 & $3 d^{3} D_{3}^{2}$ & $(3 / 2,5 / 2)^{\circ} 3$ & 59.3665 & 59.4471 & 59.4466 & 59.2598 & 59.5054 \\
\hline 23 & $3 \mathrm{~d}^{3} \mathrm{D}_{1}^{\mathrm{o}}$ & $(3 / 2,5 / 2)^{\mathrm{o}} 1$ & 59.708 & 59.7865 & 59.7907 & 59.6082 & 59.8446 \\
\hline 24 & $3 d^{3} F_{2}^{o}$ & $(1 / 2,3 / 2)^{\circ} 2$ & 60.0876 & 60.1438 & 60.1431 & 59.9749 & 60.2171 \\
\hline 25 & $3 d^{3} D_{2}^{2}$ & $(1 / 2,5 / 2)^{\circ} 2$ & 60.1617 & 60.2179 & 60.2045 & 60.0344 & 60.2940 \\
\hline 26 & $3 d^{1} F_{3}^{o}$ & $(1 / 2,5 / 2)^{\circ} 3$ & 60.197 & 60.2627 & 60.2484 & 60.0754 & 60.3337 \\
\hline 27 & $3 \mathrm{~d}^{1} \mathrm{P}_{1}^{\mathrm{o}}$ & $(1 / 2,3 / 2)^{\mathrm{o}} 1$ & 60.6903 & 60.8225 & 60.8212 & 60.6279 & 60.8461 \\
\hline 28 & $2 s 2 p^{6} 3 s^{3} S_{1}$ & $(1 / 2,1 / 2) 1$ & & 63.3306 & 63.3306 & 63.2125 & 63.3658 \\
\hline 29 & $3 \mathrm{~s}{ }^{1} \mathrm{~S}_{0}$ & $(1 / 2,1 / 2) 0$ & & 63.7925 & 63.7925 & 63.6986 & 63.8049 \\
\hline 30 & $3 \mathrm{p}^{3} \mathrm{P}_{0}^{\mathrm{o}}$ & $(1 / 2,1 / 2)^{\circ} 0$ & & 65.7338 & 65.7377 & 65.6346 & 65.7726 \\
\hline 31 & $3 \mathrm{p}^{3} \mathrm{P}_{1}^{\mathrm{o}}$ & $(1 / 2,1 / 2)^{\mathrm{o}} 1$ & 65.601 & 65.7687 & 65.7703 & 65.6676 & 65.8047 \\
\hline 32 & $3 \mathrm{p}^{3} \mathrm{P}_{2}^{\mathrm{o}}$ & $(1 / 2,3 / 2)^{\circ} 2$ & & 65.9299 & 65.9285 & 65.8380 & 65.9792 \\
\hline 33 & $3 p^{1} P_{1}^{o}$ & $(1 / 2,3 / 2)^{\mathrm{o}} 1$ & 65.923 & 66.0723 & 66.0718 & 65.9782 & 66.1267 \\
\hline 34 & $3 d^{3} D_{1}$ & $(1 / 2,3 / 2) 1$ & & 69.0162 & 69.0269 & 68.9221 & 69.0744 \\
\hline 35 & $3 d^{3} D_{2}$ & $(1 / 2,3 / 2) 2$ & & 69.0351 & 69.0386 & 68.9323 & 69.0920 \\
\hline 36 & $3 d^{3} D_{3}$ & $(1 / 2,5 / 2) 3$ & & 69.0672 & 69.0606 & 68.9518 & 69.1237 \\
\hline 37 & $3 d^{1} D_{2}$ & $(1 / 2,5 / 2) 2$ & 69.282 & 69.4358 & 69.4352 & 69.3247 & 69.4813 \\
\hline 38 & $2 s^{2} 2 p^{5} 4 s^{3} P_{2}^{o}$ & & & 71.8710 & 71.8754 & 71.6517 & \\
\hline 39 & $2 s^{2} 2 p^{5} 4 s^{1} P_{2}^{o}$ & & 71.860 & 71.9150 & 71.9197 & 71.6983 & \\
\hline 55 & ${ }^{3} \mathrm{P}_{2}^{\mathrm{o}}$ & & & 74.0927 & 74.1062 & 73.9033 & \\
\hline 56 & $2 s^{2} 2 p^{5} 4 d^{3} F_{3}^{o}$ & $(3 / 2,3 / 2)^{\circ} 3$ & & 74.1082 & 74.1151 & 73.8994 & \\
\hline 57 & ${ }^{1} \mathrm{D}_{2}^{\mathrm{o}}$ & & & 74.1526 & 74.1595 & 73.9456 & \\
\hline 85 & $2 \mathrm{~s} 2 \mathrm{p}^{6} 4 \mathrm{~d}^{1} \mathrm{D}_{2}$ & $(1 / 2,5 / 2) 2$ & & 84.0504 & 84.0501 & 83.9258 & \\
\hline 86 & $4 \mathrm{f}^{3} \mathrm{~F}_{2}^{\mathrm{o}}$ & $(1 / 2,5 / 2)^{\circ} 2$ & & 84.4770 & 84.4789 & 84.3462 & \\
\hline 87 & $4 f^{3} F_{3}^{2}$ & $(1 / 2,5 / 2)^{\circ} 3$ & & 84.4793 & 84.4801 & 84.3481 & \\
\hline 88 & $4 f^{3} \mathrm{~F}_{4}^{3}$ & $(1 / 2,7 / 2)^{\circ} 4$ & & 84.4853 & 84.4839 & 84.3522 & \\
\hline 89 & $4 \mathrm{f}^{1} \mathrm{~F}_{3}^{\mathrm{o}}$ & $(1 / 2,7 / 2)^{\circ} 3$ & & 84.4957 & 84.4953 & 84.3621 & \\
\hline$\infty$ & $2 \mathrm{~s}^{2} 2 \mathrm{p}^{52} \mathrm{P}_{3 / 2}^{\mathrm{o}} \infty l$ & & 92.760 & & - & & 92.8398 \\
\hline
\end{tabular}

SS calculations with statistical model scaling factors $\lambda_{n l}=1.38351 .15061 .08371 .05641 .01751 .03901 .05111 .01771 .01911 .0755$ in $1 \mathrm{~s} 2 \mathrm{~s} 2 \mathrm{p}$... $4 \mathrm{f}$ order. 
Table 8. Selected transition probabilities $A \cdot \mathrm{s}$ of Fe XVII, for electric dipole E1 type transitions also in velocity formulation as second entries, computed by SUPERSTRUCTURE with and without 2-body FS-terms (columns $\mathrm{Ss}^{+}$and $\mathrm{Ss}^{-}$) and MCDF, and miscellaneous results: E1 - from BPRM, M1 $-A^{\mathrm{M} 1}$. s by Bhatia \& Doschek (1992) employing (11) rather than full (10), E2 - from BPRM. The quantity $a \mathrm{e} b$ stands for $a \times 10^{b}$.

\begin{tabular}{|c|c|c|c|c|c|c|}
\hline$i$ & $j$ & type & MCDF & $\mathrm{Ss}^{+}$ & $\mathrm{Ss}^{-}$ & misc. \\
\hline \multirow[t]{2}{*}{3} & 1 & E1 & $9.63 \mathrm{e} 11$ & $9.39 \mathrm{e} 11$ & $9.42 \mathrm{e} 11$ & $9.39 \mathrm{e} 11$ \\
\hline & & & $9.24 \mathrm{e} 11$ & $8.43 \mathrm{e} 11$ & $8.51 \mathrm{e} 11$ & $9.44 \mathrm{e} 11$ \\
\hline \multirow[t]{2}{*}{5} & 1 & E1 & $8.38 \mathrm{e} 11$ & $8.00 \mathrm{e} 11$ & $7.98 \mathrm{e} 11$ & $8.01 \mathrm{e} 11$ \\
\hline & & & $8.02 \mathrm{e} 11$ & $7.76 \mathrm{e} 11$ & $7.73 \mathrm{e} 11$ & $8.08 \mathrm{e} 11$ \\
\hline \multirow[t]{2}{*}{17} & 1 & E1 & $9.42 \mathrm{e} 10$ & $8.89 \mathrm{e} 10$ & $8.23 \mathrm{e} 10$ & 7.61e10 \\
\hline & & & $8.73 \mathrm{e} 10$ & $8.27 \mathrm{e} 10$ & $7.65 \mathrm{e} 10$ & $7.49 \mathrm{e} 10$ \\
\hline \multirow[t]{2}{*}{23} & 1 & E1 & $6.01 \mathrm{e} 12$ & $5.72 \mathrm{e} 12$ & $5.73 \mathrm{e} 12$ & $5.96 \mathrm{e} 12$ \\
\hline & & & $5.65 \mathrm{e} 12$ & $5.39 \mathrm{e} 12$ & $5.41 \mathrm{e} 12$ & $5.69 \mathrm{e} 12$ \\
\hline \multirow[t]{2}{*}{27} & 1 & E1 & $2.47 \mathrm{e} 13$ & $2.52 \mathrm{e} 13$ & $2.52 \mathrm{e} 13$ & $2.30 \mathrm{e} 13$ \\
\hline & & & $2.32 \mathrm{e} 13$ & $2.40 \mathrm{e} 13$ & $2.41 \mathrm{e} 13$ & $2.19 \mathrm{e} 13$ \\
\hline \multirow[t]{2}{*}{33} & 1 & E1 & $3.29 \mathrm{e} 12$ & $3.25 \mathrm{e} 12$ & $3.25 \mathrm{e} 12$ & $3.32 \mathrm{e} 12$ \\
\hline & & & $3.30 \mathrm{e} 12$ & $3.39 \mathrm{e} 12$ & $3.38 \mathrm{e} 12$ & $3.49 \mathrm{e} 12$ \\
\hline 6 & 1 & M1 & $1.80 \mathrm{e} 5$ & $1.74 \mathrm{e} 5$ & $1.61 \mathrm{e} 5$ & $4.96 \mathrm{e}+4$ \\
\hline 9 & 1 & M1 & $6.81 \mathrm{e} 3$ & $3.31 \mathrm{e} 3$ & $4.43 \mathrm{e} 3$ & $5.94 \mathrm{e}+4$ \\
\hline 12 & 1 & M1 & $4.24 \mathrm{e} 3$ & $4.98 \mathrm{e} 3$ & $4.34 \mathrm{e} 3$ & $2.20 \mathrm{e}+3$ \\
\hline 13 & 1 & M1 & $2.03 \mathrm{e} 5$ & $1.77 \mathrm{e} 5$ & $1.79 \mathrm{e} 5$ & $1.99 \mathrm{e}+5$ \\
\hline 28 & 1 & M1 & $1.93 \mathrm{e} 4$ & $1.97 \mathrm{e} 4$ & $1.76 \mathrm{e} 4$ & $2.33 \mathrm{e}+1$ \\
\hline 34 & 1 & M1 & $2.10 \mathrm{e} 3$ & $5.31 \mathrm{e} 3$ & $8.25 \mathrm{e} 3$ & $1.67 \mathrm{e}-1$ \\
\hline 7 & 1 & E2 & $5.24 \mathrm{e} 08$ & $5.14 \mathrm{e} 08$ & $5.16 \mathrm{e} 08$ & $5.15 \mathrm{e} 08$ \\
\hline 10 & 1 & E2 & $5.63 \mathrm{e} 08$ & $5.62 \mathrm{e} 08$ & $5.60 \mathrm{e} 08$ & $5.52 \mathrm{e} 08$ \\
\hline 14 & 1 & E2 & $6.77 \mathrm{e} 08$ & $6.63 \mathrm{e} 08$ & $6.62 \mathrm{e} 08$ & $6.69 \mathrm{e} 08$ \\
\hline 35 & 1 & E2 & $1.86 \mathrm{e} 07$ & $2.52 \mathrm{e} 07$ & $4.01 \mathrm{e} 07$ & $5.85 \mathrm{e} 07$ \\
\hline 37 & 1 & E2 & $1.09 \mathrm{e} 10$ & $1.08 \mathrm{e} 10$ & $1.08 \mathrm{e} 10$ & $1.10 \mathrm{e} 10$ \\
\hline 85 & 1 & E2 & $3.00 \mathrm{e} 09$ & $2.98 \mathrm{e} 09$ & $2.98 \mathrm{e} 09$ & \\
\hline 2 & 1 & M2 & $2.25 \mathrm{e} 5$ & $2.17 \mathrm{e} 5$ & $2.17 \mathrm{e} 5$ & \\
\hline 18 & 1 & M2 & $6.16 \mathrm{e} 6$ & $2.58 \mathrm{e} 6$ & $2.63 \mathrm{e} 6$ & \\
\hline 21 & 1 & M2 & $1.13 \mathrm{e} 6$ & $6.27 \mathrm{e} 5$ & $5.44 \mathrm{e} 5$ & \\
\hline 24 & 1 & M2 & $4.47 \mathrm{e} 5$ & $8.28 \mathrm{e} 5$ & $8.79 \mathrm{e} 5$ & \\
\hline 25 & 1 & M2 & $2.73 \mathrm{e} 5$ & $4.15 \mathrm{e} 6$ & $4.14 \mathrm{e} 6$ & \\
\hline 32 & 1 & M2 & $8.44 \mathrm{e} 5$ & $8.02 \mathrm{e} 5$ & $8.02 \mathrm{e} 5$ & \\
\hline 20 & 1 & E3 & $2.83 \mathrm{e} 5$ & $2.82 \mathrm{e} 5$ & $2.85 \mathrm{e} 5$ & \\
\hline 22 & 1 & E3 & $3.52 \mathrm{e} 5$ & $3.61 \mathrm{e} 5$ & $3.60 \mathrm{e} 5$ & \\
\hline 26 & 1 & E3 & $4.00 \mathrm{e} 5$ & $3.94 \mathrm{e} 5$ & $3.93 \mathrm{e} 5$ & \\
\hline 56 & 1 & E3 & $3.87 \mathrm{e} 4$ & $1.48 \mathrm{e} 5$ & $1.49 \mathrm{e} 5$ & \\
\hline 87 & 1 & E3 & $1.23 \mathrm{e} 5$ & $1.92 \mathrm{e} 5$ & $2.75 \mathrm{e} 5$ & \\
\hline 89 & 1 & E3 & $3.36 \mathrm{e} 6$ & $3.64 \mathrm{e} 6$ & $3.56 \mathrm{e} 6$ & \\
\hline
\end{tabular}

\section{References}

Berrington, K. A., Eissner, W. B., \& Norrington, P. H. 1995, Comput. Phys. Commun., 92, 290

Bhatia, A. K., \& Doschek, G. A. 1992, At. Data Nucl. Data Tables, 52,1

Blume, M., \& Watson, R. E. 1962, Proc. R. Soc., 270A, 127

Brickhouse, N. S., Dupree, A. K., \& Young, P. R. 2001, ApJ, 562, L75

Chen, G.-X., \& Pradhan, A. K. 2002, Phys. Rev. Lett., 89, 013202

Chen, G.-X., Pradhan, A. K., \& Eissner, W. 2003, J. Phys. B, 36, 453 - CPE02

Cornille, M., Dubau, J., \& Jacquemot, S. 1994, At. Data Nucl. Data Tables, 58,1

Cunto, W., Mendoza, C., Ochsenbein, F., \& Zeippen, C. J. 1993, A\&A, 275, L5 (TOPbase). The website addresses are http://vizier.u-strasbg.fr/OP.html and http://heasarc.gsfc.nasa.gov

Eissner, W., Jones, M., \& Nussbaumer, H. 1974, Comput. Phys. Commun., 8, 270

Eissner, W., \& Zeippen, C. J. 1981, J. Phys. B, 14, 2125

Hummer, D. G., Berrington, K. A., Eissner, W., et al. 1993, A\&A, 279, 298 - IP

Layzer, D. 1959, Ann. Phys. (N.Y.), 8, 271

Lee, J. C., Ogle, P. M., Canizares, C. R., et al. 2001, ApJ, 554, L13

Nahar, S. N. 2000, A\&AS, 127, 253

Nahar, S. N., \& Pradhan, A. K. 1999, A\&AS, 135, 347

Nahar, S. N., \& Pradhan, A. K. 2000, Phys. Scr., 61, 675

Nahar, S. N., Delahaye, F., Pradhan, A. K., \& Zeippen, C. J. 2000, A\&AS, 144, 141

NIST: www.nist.gov

Parpia, F. A., Fischer, C. F., \& Grant, I. P. 1996, Comput. Phys. Commun., 94, 249

Safronova, U. I., Namba, C., Murakami, I., Johnson, W. R., \& Safronova, M. S. 2001, Phys. Rev. A, 64, 012507

Scott, N. S., \& Burke, P. G. 1980, J. Phys. B, 12, 4299

Scott, N. S., \& Taylor, K. T. 1982, Comput. Phys. Commun., 25, 347

Seaton, M. J. 1986, J. Phys. B, 19, 2601

The Opacity Project vols $1 \& 2$, compiled by the Opacity Project Team: Institute of Physics, London UK 1995 and 1996 - OP 